\title{
Historical assessment approach of the evolution of the toxic trace element contents, transformation, distribution and redistributions, environmental risk levels and stability of Jbel Ressas tailings and agricultural soil (N-E Tunisia), to predict their management plan
}

\section{Rawya Nassraoui}

CERTE: Centre de Recherche et des Technologies des Eaux de Borj Cedria

Dalila Fkih Romdhan

CERTE: Centre de Recherche et des Technologies des Eaux de Borj Cedria Abdelkrim Charef ( $\sim$ Abdelkrim.Charef@certe.rnrt.tn )

Technopole de Borj Cédria: Technopole de Borj-Cedria Jamel Ayari

CERTE: Centre de Recherche et des Technologies des Eaux de Borj Cedria

\section{Research Article}

Keywords: Toxic trace elements, Tailings-soils, Historical evolution, Ttotal-mobile pollutants, Uts-IR stability index, Health risk

Posted Date: January 19th, 2022

DOI: https://doi.org/10.21203/rs.3.rs-1162378/v1

License: (c) (i) This work is licensed under a Creative Commons Attribution 4.0 International License. Read Full License 


\section{Abstract}

The jbel Ressas Pb-Zn mining wastes that had more than 600,000 m3 and their surrounding agricultural soil, that are in Northeastern Tunisia had ecological a high hazards. To suggest the wastes protection and soil remediation plan the evaluation of the historical evolution of their total and labile TTE contents, stability and distributions since their abundance (1952) and until today, which is not often possible, was a crucial step. The of Pb, $\mathrm{Zn}$ and $\mathrm{Cd}$ quantities in the initial wastes were $46640 \mathrm{t}, 134780 \mathrm{t}$ and $1150 \mathrm{t}$. the released $\mathrm{Pb}, \mathrm{Zn}$ and Cd quantities in 2009 was $50 \%$ and in 2021 was $22.6 \%$. The remained quantities are $15.6 \mathrm{t}$ of $\mathrm{Pb}, 64.2 \mathrm{t}$ de $\mathrm{Zn}$ and $0.4 \mathrm{t}$ de $\mathrm{Cd}$ that presented a worrying environmental hazard. The pollutants speed migration was accelerated, particularly during the last 10 years. Thus, the risk of these pollutant sources is still high. Of the TTE that migrated from the tailings, only $6.1,4.8$, and $4.1 \%$ of $\mathrm{Pb}, \mathrm{Zn}$, and $\mathrm{Cd}$, respectively were retained in soil. However, the soil potential ecological risk (Eri.) was high. From 1952 and until 2009 around $60 \%$ of the TTE tailings have been mobilized and from 2009 to 2021 around $6 \%$. The estimation of the future evolution of redistributions and transformations of current TTE showed that the risk of Jbel Ressas residues is worrying. The whole-soil removal $\left(U_{t s}\right)$ and relative binding intensity index $\left(I_{R}\right)$ of the TEE in initial tailings sediments and soil $\approx 1$ meaning that had any environemental risk. The $U_{t s}$ and $I_{R}$ evolution from 1952 and until today showed that the TTE stability and risk level increased with exposition time. Therefore, the overall historical assessment is of great interest in order to suggest solutions for polluted areas.

\section{Introduction}

The mining activities often generate large wastes volumes that were abandoned caused a widespread public concern. Although they were deposed several decades ago, they still carrying significant environmental risks. Their very high toxic trace elements (TTE) contents were often eroded towards the surrounding areas including the agricultural soils and contaminated it. Then these pollutants could be introduced into food-chain which represents a human health hazard (Zornoza et al., 2012). In order to management this of pollution sources type and contaminated soils, it is essential to make a detailed assessment. In order to carry out their global evaluations, several mineralogical, chemical, geophysical and statistical static studies and others have been developed (Navarro et al. 2008; Acosta et al. 2011; Conesa et al. 2011; Martínez-Pagán et al. 2011). However, these approaches believed incomplete to identify the appropriate remediation technique. In order to understand how to efficient manage in a sustainable manner these wastes and avoid the environmental problems associated with inaccurate risk assessment, exploring the waste history is a necessary step to the challenge. This could be done by identifying the evolution of the total pollutant content of the mine waste since its deposition and until today in order to predict its future risks. Secondly, it is necessary to evaluate the fate of the toxic elements released by the landfills towards the neighboring agricultural soils. Indeed, the evolution of TTE contents and their potential ecological risk factors (Eri) (Muller 1969; Hakanson 1980; Salomons and Forstner 1984; Abrahim and Parker 2007) in the agricultural soil, from ancient times to the present and probably in the future, will allow us to clarify whether or not the quantities of pollutants released by these dumps have all been trapped by the soil and their distribution.

Quantifying the total metal allows to have an idea about their abundance. However, it is insufficient to have an exact idea about their toxicity levels and their environmental and human health impacts. To assess the exact potential environmental risk of polluted site, the identification and quantification of the evolution of the TTE 
bioavailability in the residues and the mobility factors (MF) from the initial waste deposition to the present day were essential (Kabata-Pendias 1993; Dean 2007; Rao et al. 2008; Camden-Smith et al. 2014).

Due to the prolonged incubation period of TTE in the mine wastes and their additions to soil (from residues) and the competition between sediment compounds and associated complex processes, changes in the redistribution and transformation of the pollutants between the different sediment fractions will have to take place. To quantitatively explore the transformation pathway(s) and kinetics of TTE, the equilibrium parameters proposed by Banin et al. (1990) were required. These are the whole soil index $\left(U_{t s}\right)$ and the relative bending intensity index (RI). This evaluation will also allow to assess the of stability evolution degrees of the tailings and agricultural soil.

In this way, the assessment will determine the past, present and future health risk and the establishment of a short or long term management plan.

The Jebel Ressas tailings and the surrounding agricultural soils (North of Tunisia) pose serious environmental problems. In this site, more than $600,000 \mathrm{~m}^{3}$ of mining waste (3 dams: DI, DII and DIII) include high amounts of $\mathrm{Pb}, \mathrm{Zn}$ and $\mathrm{Cd}$ (e.g. Ghorbel 2012) of which an important part has moved to the surrounding areas. To assess the pollution status of this site, physicochemical properties and total and bioavailable concentrations of TTEs of mine tailings and local agricultural soil have been performed (e.g. Ghorbel 2012; Souissi et al. 2014; Elouear et al. 2016). However, a historical assessment of the total metal contents and their labile fractions of the mine wastes and soil and their distribution is missing, which is necessary to define a management plan for the pollution sources of and soil rehabilitation.

In order that the quantitative assessment to be complete, it was also necessary to specify the evolution of the TTE mobile portions and their distribution in tailings and soil. The quantification of the of the redistribution and transformation evolutions of the TTE and their stability levels signifying their level of risk could be ensured by the calculation of the equilibrium parameters that are the whole soil $\left(\mathrm{U}_{\mathrm{ts}}\right)$ and the binding intensity (reduced partition index: $I_{R}$ ) of the TTE (Han and Banin 1999; Fengxia and Wenbao 2010; These parameters will make it possible to specify the quantities of total and labile TTE remaining in the waste and retained by the soil and which could present an environmental and health risk. The accuracy of the stability level and subsequent risk of these pollutants are also critical. The available information on the initial waste characteristics, which is still lacking elsewhere and the samples taken in 2009 and 2021, will be the tools for the assessment.

Therefore, the objectives of this study were to specify the assessment of (i) the past and present levels of total and available $\mathrm{Pb}, \mathrm{Zn}$ and $\mathrm{Cd}$ (historical evolution) in tailings and soils, as well as their distributions and potential ecological risk and mobility factors, and (ii) the pathways and kinetics of transformations of $\mathrm{Pb}, \mathrm{Zn}$ and $\mathrm{Cd}$ native to the tailings and loaded from the wastes into agricultural soils, in order to provide a management plan of the dams to limit or stop the pollutants migration and remediate the soil.

\section{Material And Methods}

\section{Study area}

The Jebel Ressas mine site is located 30 km southeast of Tunis (N-E, Tunisia) and at 36 $36^{\prime} 33.02^{\prime \prime}, 10^{\circ} 18^{\prime} 56.58^{\prime \prime}$ (Fig. 1). The stratiform and vein mineralizations (in the form of open space llages) are of $\mathrm{Pb}$ and $\mathrm{Zn}$. Both ore 
types are found in the Upper Jurassic Ressas Formation (bioclastic limestones) and in contact with Triassic rocks (Sainfeld 1952). The main ores minerals are Galena (PbS), Sphalerite ( $\mathrm{ZnS})$ and Smithsonite $\left(\mathrm{ZnCO}_{3}\right)$.

From 1880 to 1956, the mine exploitation was in three discontinuous periods. The 70 years of activity produced huge quantities of wastes that were divided into three dumps (DI, DII and DIII) (Fig. 2). The surface and total volume of these tailings are respectively about 12 ha and $600,000 \mathrm{~m}^{3}$. From the beginning, the dumps were totally exposed and without any management. Their protection lack had greatly accelerated their alteration and erosion. But, on the dump surfaces a carbonate crust was quickly precipitated which impermeabilized them (Ghorbel 2012, Nassraoui 2021; Nassraoui et al. submitted).Thus, the wind distribution of their pollutants was made difficult if not impossible.

The Jbel Ressas wastes are surrounded by agricultural soils, mostly planted with olive trees. The average precipitation and temperature in Jbel Ressas region are around 500 mmyear $^{-1}$, and $25^{\circ} \mathrm{C}$, respectively (INM 2020). In the Ressas region, the west to North West is the main regional wind directions.

\section{Field sampling and analytical methods}

Eight cores (four in each) were taken in the DII and DIII dumps. Taking into account the wind directions, topography, slope, and texture, the same eight plots in the tailings and 32 plots in the soil were sampled in 2009 , and 2021. In each plot (4 m × $4 \mathrm{~m}$ ), eight equidistant $10 \times 10 \times 20 \mathrm{~cm}$ volumes of sediment were collected and then mixed. The composite sample was successively sieved through a 2-mm stainless steel sieve, transferred to dry polyethylene bags, freeze-dried, and stored in a cold room for further analysis.

The tailings and soil granulometric analysis was carried out using Robinson pipette method. The tailings and soil mineralogical composition was analyzed by using an by X-ray diffraction (XRD) SIEMENS D-5000 type with a scanning speed of $1^{\circ} / 2 \theta$ min and Cu-Ka radiation (40 kV, $\left.20 \mathrm{~mA}\right)$ from $0^{\circ}$ to $70^{\circ}$ (Van der Marel 1966).

The soil/water ratio 1:5 after one-hour mechanical shaking $\mathrm{pH}$ and electrical conductivity (EC) were measured by pH meter LPH 230 T-type and conductivity meter model ORION 150. The Ethylenediamine complex was used to determine the cation exchange capacity (CEC) (Bergaya and Vayer 1997). The calcium carbonate $\left(\mathrm{CaCO}_{3}\right)$ and total organic carbon (TOC) were determined by using the Bernard calcimeter method and the walkley-black titration method (Walkley and Black 1934), respectively. The total heavy metal concentration analysis, tailings and soil samples were processed and the obtained solution analyzed by flame atomic absorption spectrometry (AAS) equipped with a graphite furnace.

To ensure the extraction of the maximum quantities of bioavailable TTE fractions, many simple and complex procedures (sequential extraction) were tested (e.g. Tessier et al., 1979; Quevauviller 1998; Kabata-Pandias 2004; Sliti et al. 2019, Maiz et al. 2000; Favas et al. 2011). The obtained data showed that the most appropriated TTE extraction procedure is the BCR method (European Community Bureau of Reference) (Table 1) (Nassraoui et al. submitted).

The recovery percentage of sequential extraction is:

$$
\% \text { Recovery }=\frac{((\mathrm{F} 1+\mathrm{F} 2+\mathrm{F} 3+\mathrm{F} 4)}{(\text { total concentration })} * 100(\mathrm{Eq} .1)
$$


$20 \%$ of analyzed samples were replicated. To ensure the accuracy and reproducibility of each extraction step (Tessier et al. 1979; Ure et al. 1993), the use of NIST 2709a and a blank sample were often run. Each value was considered only if it was below $2 \%$, compared to the certified value. The BCR-701 reference was also used. The non reproducible values were replicated.

All analyses were carried out respecting the quality assurance/quality control (QA/QC) protocol.

\section{Potential ecological risk and mobility factors}

The potential ecological risk factor was used to quantitatively express the potential ecological risk (RI). It was calculated as follows: $\mathrm{RI}=\sum \mathrm{E}_{\mathrm{i}}$ and $\mathrm{E}_{\mathrm{i}}=\mathrm{T}_{\mathrm{i}} / \mathrm{B}_{\mathrm{i}}$ (Eq. 2)

Were $T_{i}=$ the toxic response factor of heavy metal: $T_{Z n}=1 ; T_{P b}=5 ; T_{C d}=30$.

$C_{i}=$ the concentration of $i$ element and $B_{i}$ is the background value of the trace element $i$.

Hakanson (1980) proposed five levels of Ei: $E_{i}<0$ low potential ecological risk; $40<E_{i}<80$ moderate potential ecological risk; $80<\mathrm{E}_{\mathrm{i}}<160$ considerable potential ecological risk;

$160<\mathrm{E}_{\mathrm{i}}<320$ high potential ecological risk; $\mathrm{E}_{\mathrm{i}}>320$ very high ecological risk at hand for the substance in question.

The mobility factor (MF) was calculated as follows using the equation:

$M F=((F 1+F 2+F 3) /(F 1+F 2+F 3+F 4)) * 100$ (Davidson et al. 1998) (Eq. 3)

The ArcGis 10.6 and global mapper 21 were used to dress the hydrographic network and flow direction.

\section{Redistribution Index and relative binding intensity of metals}

$\mathrm{U}_{\mathrm{tf}}$ used to describe the fractional evolution of component $\mathrm{i}$ in amended soil with ionic trace metal elements to the quasi-equilibrium state as in control soil. This fractional redistribution index was defined as follows:

$U_{t f}=F_{a} / F_{c}($ Banin et al. 1990) (Eq. 4)

Where $F_{a}$ is the fraction of the metal bound to a given component in amended soil, $F_{c}$ is the fraction of the metal bound to the same component in control soil.

$\mathrm{U}_{\mathrm{ts}}$ was calculated to describe the whole-soil removal of metal bound to a given component from equilibrium state to the incubated metal-amended soil (Banin et al. 1990).

$U_{t s}=\Sigma_{i}^{k}\left(F_{i} \times U_{t f i}\right)($ Eq. 5)

where $\mathrm{i}=1$ to $\mathrm{k}$ sequential extraction step (1: least aggressive, $\mathrm{k}=4$ : most aggressive),

By definition, $U_{t s}=1$ corresponding the equilibrium state.

In the studied site, the $F_{c}$ is the percentage of the total metal quantities that was bound to each sediment fraction within the initial wastes and considered control regional soil where the TTE were in quasi-equilibrium state. The $F_{a}$ 
was the percentage of the total amount of metal that was bound to a same sediment fraction in abandoned wastes and cultivated soils. When the environment is in a quasi-equilibrium state, $\mathrm{U}_{\mathrm{tf}}$ values equals 1.

The reduced partition index $\left(I_{R}\right)$ is the binding intensity of TTE to soil sediments (Banin et al. 1990). $I_{R}$ was defined as follows:

$\mathrm{I}=\sum_{\mathrm{n}=1}^{\mathrm{k}}(\mathrm{FiX}(\mathrm{i})) \mathrm{n}$ and $\mathrm{I}_{\mathrm{R}}=\mathrm{l} /\left(\mathrm{k}^{\mathrm{n}}\right)($ Eq. 6)

In Jbel Ressas, Fi was the percentage of the total amount of metal that was bound to component $\mathrm{i}$ in abandoned wastes and active soil. $\mathrm{n}$ was arbitrary equal 2 . $\mathrm{I}_{\mathrm{R}}=$ around 1 when the highest TTT amount was bound to the residual fraction (equilibrium sate) and $I_{R} \approx 0.063$ when all pollutants transformed to soluble forms as the sequential extraction steps was four.

\section{Results And Discussion}

\section{Tailings and soil characteristics}

The four core drills curried out in DII and DIII dumps that were that were exposed long exposed (Since 195) to severe climatic conditions showed 5 and six carbonate layers with around 1 to $2.5 \mathrm{~m}$ thick and separated by clay layers, successively. In DII dump, sulfides (sphalerite and galena) and in DIII dump Cerusite, Smithsonite and Hydrozincite are the main minerals. Traces of gypsum are also present in DIII whose frequency increased with the frequency of the zinciferous minerals presence. The dominant grain size fraction was fine $(<63 \mu \mathrm{m})$. Their mean percentages in DII and DIII were 83 and $72 \%$, respectively. The physicochemical characteristics (pH, EC, CEC, TOC, phyllosilicate) are given in Table 1 . The initial wastes were mostly composed of silt (72\%), clay (15\%) and sand particles $(13 \%)$. The $\mathrm{pH}$ was around the neutrality. Due to the clay proportions, the mean cation exchange capacity values were relatively high. The mean TOC concentration was $2.1 \%$ (maximum $3.28 \%$ ) (Table 2). The Carbonates were the major's mineral of the actual wastes. Compared to initial wastes, a decrease tendency of pH values (from 6.7 to 7.6 ) and carbonate percentages (from around 60 to 55\%) was observed. While an important increase of the EC values detected.

The carbonates percentage ranges were high in Jebel Ressas agricultural soil (from 7 to $100 \%$ ). It characterized by wide alkaline $\mathrm{pH}$ ranging from 6.70 to 9.13 with a mean value 7.6. Thus, the high carbonates amount

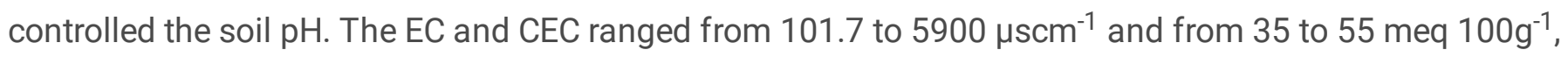
respectively. The minimum and maximum values of the soil organic matter of Jebel Ressas were from 0.34 to $2.95 \%$ (Table 3).

\section{Tailings total trace element content and mobility Global balance}

The high pollutant concentrations of the initial residues presented a high health risk. The TTE concentrations were variable among residues to one another. The average concentrations in DIl were $2.13 \%$ of $\mathrm{Pb}, 6.33 \%$ of $\mathrm{Zn}$ and $521 \mathrm{mg} \mathrm{kg}^{-1}$ of $\mathrm{Cd}$ and $2.74 \%$ of $\mathrm{Pb}, 7.56 \%$ of $\mathrm{Zn}$ and $683 \mathrm{mg} \mathrm{kg}^{-1}$ of $\mathrm{Cd}$ in DIII. Some traces of $\mathrm{Ag}, \mathrm{Mn}$ and $\mathrm{Cr}$ were signaled. 
Taking into account the initial average pollutants concentrations of the DII and DIII, the mineralogical composition

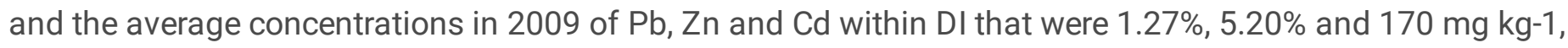
respectively (Ghorbel 2012), the masses of $\mathrm{Pb}, \mathrm{Zn}$ and $\mathrm{Cd}$ of the initial mine waste were 46640, 134780 and 1150 $\mathrm{t}$, respectively. The content of these damps became $22180 \mathrm{t}$ of $\mathrm{Pb}, 78560 \mathrm{t}$ of $\mathrm{Zn}$ and $508 \mathrm{t}$ of $\mathrm{Cd}$ in 2009. In 2021, the wastes involved $10300 \mathrm{t}$ of $\mathrm{Pb}, 27500 \mathrm{t}$ of $\mathrm{Zn}$ and $291 \mathrm{t}$ of $\mathrm{Cd}$. Therefore, these mining wastes lost since 1952 around $70 \%$ of $\mathrm{Pb}$ and $\mathrm{Cd}$ and $79 \%$ of $\mathrm{Zn}$. Thus, these dumps retained $15.6 \mathrm{t}$ of $\mathrm{Pb}, 64.2 \mathrm{t}$ de $\mathrm{Zn}$ and $0.4 \mathrm{tde} \mathrm{Cd}$ that presented a worrying environmental hazard.

As around $50 \%$ of the three trace elements left the waste over 60 years and about $22.6 \%$ over 10 years, the rate of migration of pollutants had accelerated over the last period. Thus, the risk from these pollutant sources is still high.

\section{Toxic trace elements mobility}

Following the crystallization of the impermeable carbonate crust (Ghorbel 2012, Nassraoui 2021; Nassraoui et al. submitted), the wind erosion of pollutants had significantly decreased. Thus, it was argued that only mobile fractions of the tailings TTE were likely migrated towards their surrounding areas. Therefore, evaluation of the TTE mobility evolution was imperative. The chemical behavior of toxic elements and the levels of their potential environment risk depend on the forms in which they were bounded to solid phase (Allen 1997). The sequential extraction of jbel Ressas material showed that between $83 \%$ and $99.6 \%$ of the $\mathrm{Pb}, \mathrm{Zn}$, and Cd from the two dumps were primarily bounded to the residual fraction. Thus, the sum of $\mathrm{Pb}$ and $\mathrm{Zn}$ bounded to the exchangeable, organic matter, and Mn oxides fractions represented less than $5 \%$ of the total TTE content. Cd was the most mobile element in the original TTE waste (13\% in DIII). Therefore, the mobility factors (MF) of Pb, Zn, and Cd in the initial wastes were 1, 4, and 18, successively. In addition, the proportions of $\mathrm{Pb}, \mathrm{Zn}$ and $\mathrm{Cd}$ in the residual fractions in DIl became 42, 29 and 10\% in 2009 and 37, 16 and 4\% in 2021, respectively. Similarly, a strong decrease in the percentages of pollutants was observed in the residual fractions of DIII. Indeed, the residual fractions contained in 2009 about $13 \% \mathrm{~Pb}$, up to $44 \% \mathrm{Zn}$ and $42 \% \mathrm{Cd}$. In 2021, 9, 37.3\% and 39\% of Pb, Zn and Cd respectively were in mobile form (Fig. 3 ).

The sum of the labile pollutants of DII in 2019 and 2021 were 73 and $81 \%$, respectively and the highest percentages were associated with organic matter.. In DIII, the sum of the mobile TTE was $67 \%$ in 2019 and 71.6 in 2021 and the majority of $\mathrm{Cd}$ was retained by exchangeable fraction. This evolution of TTE distributions among the different sediment fraction explained the increase of their MF. The Pb, Zn and Cd MF of DII became up to 58, 71 and 90 in 2009 and 63, 84 and 96 in 2021. In DIII, they also increased to be up 87, 62 and 58 in 2009 and up to 91, 79 and 61 in 2021 (Fig. 3). Hence, the TTE proportions bounded to exchangeable fraction, oxides fraction and organic matter increased with waste exposition time. The decreasing mobility orders of TTE in DII and DIII were $\mathrm{Cd}>\mathrm{Zn}>\mathrm{Pb}$ and $\mathrm{Pb}>\mathrm{Zn}>\mathrm{Cd}$, respectively.

Taking these results into account, the total mass of $\mathrm{Pb}, \mathrm{Zn}$ and $\mathrm{Cd}$ in the three landfills is $38100 \mathrm{t}$. Since the mineralogical composition of DI and DIII are comparable and about $75 \%$ of the toxic trace elements are in mobile forms, the three dumps currently contain about 28300 t of highly mobilizable TTE that present a high risk to the local environment.

\section{Total soil toxic trace elements}

\section{Toxic trace elements and distribution}


The average total concentrations of $\mathrm{Pb}, \mathrm{Zn}$, and $\mathrm{Cd}$ in the initial soil in 2009 and 2021 were 156.5, 19496, and $30910 \mathrm{mg} \mathrm{kg}^{-1}$ (Table 4). The total Pb, Zn, and Cd concentrations increased approximately 125 times in 58 years (1950 to 2009) and approximately 73 times in 12 years (2009-2021). The order of change in the 3 trace elements concentrations varied with the increase period of wastes exposure. Until 2009, the increase in soil Pb content was significantly higher than that of Zn, while the soil from 2009 to 2021 was more enriched in $\mathrm{Zn}$ than in $\mathrm{Pb}$. An increase in soil Cd content with tailings exposure time was always observed (Table 4).

The Jebel ressas MNT map shows that the highest elevation area corresponds to the tailings surfaces. The western-southwestern part of the site has the lowest elevation, while the elevations of the rest of the site are intermediate (Fig. 4). The spatial distribution of each pollutant (Table 5) and the pollutant sums showed that the site could be essentially subdivided into five zones that were distinguished by their pollution levels. The increasing order of the sums of the average concentrations of Pb, Zn and Cd in 2009 were (Table 5) Sector $3=$ $37716<$ Sector $5=17832<$ Sector $1=15282<$ Sector $2=13867<$ Sector $4=12786 \mathrm{mgkg}-1$. This order became in 2021: Sector $1=57528>$ Sector $2=40232>$ Sector $4=20211>$ Sector $3=3679>$ Sector $5=3004$ mgkg-1 (Fig. 4). In 2009 , the sectors 4 where the altitude is the lowest had the least polluted level. However in 2021 the lowest total concentration of pollutants was in sector 5 , while the soil elevation is relatively high. The sector 3 where the altitude is relatively low, it contained the highest total pollutant concentrations. Therefore, the soil altitude couldn't be considered a determining factor in pollutants distribution. However, this zonal distinction can only be virtual. Indeed, the map of hydrographic network with flow direction of Jebel Ressas showed that the low altitude zones are likely to receive the maximum amount of polluted water. However, due to the large volumes of precipitation runoff, a large part of the eroded pollutants percolated to the unsaturated zone and polluted the groundwater (Nassraoui, 2021). Thus, the only part that remained on the surface was dosed. Therefore, the surface sediment results should be viewed with caution. As reported by several authors (Boussen et al., 2013; Tembo B.D et al., 2006. Sahraoui et al., 2016), the wind pollution spreading should not be overlooked.

\section{Global mass balance of TTE}

Since all $20 \mathrm{~cm}$ of the soil slice was sampled and analyzed and the soil density is around $1.3 \mathrm{~g} \mathrm{~cm}^{-3}$, the weight of the soil surface slic closest to the polluted dumps was estimated to be $0.25 \mathrm{~km}^{2}$ of $20 \mathrm{~cm}$ deep. From the total concentration per $\mathrm{kg}$ of sediments and weight of the surface slice sediments of this soil part, the $\mathrm{Pb}, \mathrm{Zn}$, and $\mathrm{Cd}$ amounts in the initial soil were 357,356 , and $32 \mathrm{~g}$, respectively. The soil $\mathrm{Pb}, \mathrm{Zn}$, and $\mathrm{Cd}$ contents increased to approximately $70 \mathrm{t}$ of $\mathrm{Pb}, 56 \mathrm{t}$ of $\mathrm{Zn}$, and $600 \mathrm{~kg}$ of $\mathrm{Cd}$ in 2009 and 79 t, $121 \mathrm{t}$, and $435 \mathrm{~kg}$ of Cadmium in 2021, respectively. Therefore, there was a progressive pollutant masses increases in the Jbel Ressas soil with the dams exposure time. Compared to the TTE quantities released from the tailings, the soil retained only $0.2 \%$ of $\mathrm{Pb}, 1 \%$ of $\mathrm{Zn}$ and $0.05 \%$ of $\mathrm{Cd}$. Souissi et al. (2014) reported that the average $\mathrm{Pb}, \mathrm{Zn}$ and $\mathrm{Cd}$ concentrations of the first 2 meters of agricultural soil in the vicinity of the tailings were 0.38 and $0.87 \%$ and $6.11 \mathrm{mg} \mathrm{kg}^{-1}$. Thus the first two meters contained around $2223 \mathrm{t}$ of $\mathrm{Pb}, 5090 \mathrm{t}$ of $\mathrm{Zn}$ and $3.5 \mathrm{~kg}$ of $\mathrm{Cd}$. Hence, only 6.1, 4.8, and 4.1\% of Pb, Zn and $\mathrm{Cd}$, respectively of the quantities of TTE eroded from the tailings were lodged in the soil surrounding of Jbel Ressas dumps. Therefore probably, the pollutant quantities that migrated from the tailings reached large Jbel Ressas areas.

\section{Ecological risk factor ( Er')}

Compared to the Tunisian standard where the maximum concentrations of $\mathrm{Pb}, \mathrm{Zn}$ and $\mathrm{Cd}$ in agricultural soils are 100, 3 and $300 \mathrm{mg} \mathrm{kg}^{-1}$, the Jbel Ressas soil was highly polluted. 
Based on the background values proposed by Bowen (1979), the concentrations of Pb, Zn and Cd in the initial agricultural soil of the Jbel Ressas area were respectively 1.5, 4.5 and 2.5 times higher. In 2021, the average increase in ecological risk factors $\left(\mathrm{Er}^{\mathrm{i}}\right)$ of $\mathrm{Pb}, \mathrm{Zn}$ and $\mathrm{Cd}$ was about $28 \%, 70 \%$ and $30 \%$, respectively, compared to the average $\mathrm{Er}^{\mathrm{i}}$ in 2009. In 2021, the range of Eri of $\mathrm{Pb}$ in the soil of Jbel Ressas is between 14 and 3200 (mean $\mathrm{Er}^{\mathrm{i}}$ $\approx 744$ ). $97 \%$ of the soil area downstream of the tailings was at very high ecological risk. Only $3 \%$ of the soil that corresponds to the area away from the tailings had a low to considerable ecological risk. For Zn, $30 \%$ of the studied area had high potential ecological risk (160< $\left.\mathrm{Er}^{\mathrm{i}}<320\right), 47 \%, 11 \%$, and $12 \%$ showed considerable, moderate, and low ecological risk, respectively. In all agricultural soils, Cd caused a very high potential ecological risk $\left(\mathrm{Er}^{\mathrm{i}}>\right.$ 320) (Fig. 7). The order of TTE risk was $\mathrm{Cd}>\mathrm{Pb}>\mathrm{Zn}$. Therefore, the agricultural soil surrounding the three residues had a serious ecological risk that was mainly due to its high TTE content.

\section{Pollutants mobility}

From initial deposition to 2021, there was a gradual evolution of the waste physicochemical characteristics that should have a direct effect on the evolution of the soil TTE mobility. For example, based on the Pb mobility factors that were $24,21,18,36$ and 7 in sector 1 to 5 , respectively; we could subdivide the Jebel Ressas soil into five sectors (Fig. 2).

In 2009, the Pb was more stable than $\mathrm{Zn}$ and $\mathrm{Cd} .76,79,82,64$ and $94 \%$ of lead bounded in the sector 1, 2, 3, 4 and 5 to residual fractions, respectively. In all sectors, the Pb percentage ranges in the oxides fractions were from $2-18 \%$. The $\mathrm{Pb}$ percentages bounded to

Exchangeable fractions did not exceed 5\%. The organic fractions of sectors 1, 2, 3, 4 and 5 involved 9.3, 4, 14 and $4 \%$ of $\mathrm{Pb}$, respectively (Fig. 2).

The $\mathrm{Zn}$ was more mobile than $\mathrm{Pb}$. The decrease of labile percentages of $\mathrm{Zn}$ were 58 in sector 1 (F1=15, F2=18, $\mathrm{F} 3=25 \%), 53$ in sector 2 ( $F 1=15, F 2=16, F 3=22 \%), 53$ also in sector 3 (F1=14, F2=15, F3=24\%), 49 in sector 4 and $43 \%$ in sector 5 . However, the $\mathrm{Zn}$ fractions retained in the residual fraction increased from sector 1 to sector 5 (Fig. 2).

The Cd in sector 1 (55\%) and 2 (58\%) bounded more in labile than in residual fractions (45 in sector 1 and $42 \%$ in sector 2). In sector 3 , the highest percentage of $\mathrm{Cd}$ bounded to residual fraction (55\%). $21 \%$ of Cd associated to exchangeable fractions and $19 \%$ to oxides fraction. Just $5 \%$ of $\mathrm{Cd}$ fixed to organic matter fractions. In sector 4 and 5 , the percentages of $\mathrm{Cd}$ in active forms (F1+F2+F3) were 45 and $51 \%$, respectively and in residual fractions were 55 and $49 \%$, respectively.

The Jebel Ressas sectorial subdivision of agricultural soil adopted in 2009 was confirmed in 2021. However, significant variations of the TTE distribution among soil fractions.

In Sector 1, the Pb percentage bounded to exchangeable fraction was low (4\%). The essential Pb quantities bounded to organic matter (54\%) and oxides fraction (29\%). Just $14 \%$ of lead was in stable form (associated with residual fraction). $29 \%, 16 \%$ and $22 \%$ of Zn quantities bounded to exchangeable, organic matter and oxides fractions. Just 33\% bounded to residual fraction. $5 \%, 31 \%$ and $36 \%$ of $\mathrm{Cd}$ bounded to exchangeable, organic matter and oxides fractions, respectively and only $27 \%$ to residual fraction. 
In Sector 2, the highest percentage retained $\mathrm{Pb}$ by organic matter (39\%). $26 \%$ of $\mathrm{Pb}$ associated with oxides fractions and only $1 \%$ bounded to exchangeable fraction. $34 \%$ bounded to residual fraction. The $\mathrm{Zn}$ extraction data showed that the totally $\mathrm{Zn}$ quantity bounded to bioavailable fractions (F1=26\%, F2= 32\% and F3=41\%). The maximum quantities of $\mathrm{Cd}$ were in active form $60 \%$ ( $\mathrm{F} 1=2 \%, \mathrm{~F} 2=17 \%$ and $\mathrm{F} 3=42 \%)$ and $40 \%$ involved in residual fraction.

In Sector 3, low percentages of $\mathrm{Pb}(4 \%)$ and $\mathrm{Cd}(10 \%)$ bounded to exchangeable fractions. $23 \%$ of $\mathrm{Pb}$ and $17 \%$ of $\mathrm{Cd}$ retained by the oxides fractions. In organic matter, the percentages of $\mathrm{Pb}$ and $\mathrm{Cd}$ were $37 \%$ and $17 \%$, respectively. The majority of $\mathrm{Cd}(58 \%)$ and $\mathrm{Pb}(36 \%)$ fixed by residual fraction. The essential $\mathrm{Zn}$ quantity was bounded to exchangeable fraction (40\%). In oxides and organic matter fractions the percentages of Zn were $28 \%$ and $20 \%$, respectively and just $12 \%$ was fixed by residual fraction.

In Sector 4, a high $\mathrm{Pb}$ percentage was in stable form (39\% associated with residual fraction), and $61 \%$ was in labile fractions $(F 1=1 \%, F 2=37 \%, F 3=23 \%)$. A high $\mathrm{Zn}$ percentage was in labile forms as $42 \%$ was in $\mathrm{F} 1,20 \%$ in $\mathrm{F} 2$, and $38 \%$ in $\mathrm{F} 3$. For $\mathrm{Cd}$, the most percentage was in stable $(57 \%)$ fraction and $43 \%$ was in active forms $(\mathrm{F} 1=17 \%$, $\mathrm{F} 2=18 \%, \mathrm{~F} 3=8 \%)$.

In Sector 5, the high extracted $\mathrm{Pb}(92 \%)$ and $\mathrm{Cd}(45 \%)$ portions were bounded to residual fraction. The $\mathrm{Pb}$ and $\mathrm{Cd}$ were retained by $\mathrm{F} 2=\mathrm{F} 3=3 \%$ and $\mathrm{F} 2=\mathrm{F} 3=15 \%$, respectively. In the exchangeable fractions the percentage of $\mathrm{Pb}$ and $\mathrm{Cd}$ were $2 \%$ and $25 \%$, respectively. $38 \%$ and $25 \%$ of $\mathrm{Zn}$ bounded to oxides and organic matter fractions respectively. Just $4 \%$ bounded to exchangeable fraction and $32 \%$ of the $\mathrm{Zn}$ fixed by residual fraction.

In 2009, the affinity orders of $\mathrm{Pb}, \mathrm{Zn}$ and $\mathrm{Cd}$ in sectors 1, 2 and 3 (close to DIII and DII tailings) showed that the essential TTE percentages were bounded to labile fractions (F1+F2+F3). Indeed, the mobility factors (FM) in the sectors 1, 2 and 3 of the $\mathrm{Pb}$ were 86, 66, and 64, of the Zn 67, 99 and 88 and of the Cd 73, 60 and 42, respectively. The TTE affinity orders in the sectors 4 and 5 showed that the Pb and Cd were the more stables. The $\mathrm{Zn}$ in these two sectors had a high mobility that were 94 (sector 4) and 96 (sector 5). The Cd mobility factors in sector 4 and 5 were 43 and 55, respectively (Table 6). In 2021, the affinity order of Pb fraction found similar in the sectors 1, 2, 3 and 4 and essentially bounded to residual and oxide fractions. Furthermore results found that $\mathrm{Zn}$ was bounded essentially with residual fraction and organic matter. The data also showed that the $\mathrm{Cd}$ in the 5 sectors was essentially associated with residual, oxides and organic matter fractions (Table 6).

These data showed also that TTE mobility affinity orders had changed from 2009 to 2012 (Table 6) and the TTE mobility increase from 2009 to 2021. The TTE were also always more mobile close to the tailings and their lability decreased far way the contamination source, except the Zn stay elsewhere high mobile.

These summary data that included all obtained data from the studied site showed that from initial wastes deposition to 2021 an important evolution of $\mathrm{Pb}, \mathrm{Zn}$ and Cd speciation's occurred (Fig. 7). Indeed, first the TTE were essentially in stable forms, particularly the $\mathrm{Pb}$ and $\mathrm{Zn}$. After that, an important increase of the mean percentages of labile pollutant portions was observed. In 2009, the $\mathrm{Pb}$, $\mathrm{Zn}$ and $\mathrm{Cd}$ percentages bounded to mobile fractions (F1+F2+F3) were 21, 51 and $51 \%$, respectively and to residual fraction were 79,50 and $49 \%$, respectively (Fig. 7). In 2021, the mobile $\mathrm{Pb}, \mathrm{Zn}$ and Cd fractions had increased to be 57, 84 and $55 \%$ and their stable forms declined to up 43, 16 and 45\%. These data also showed that the TTE mobility order had changed from 2009 to 2012. It was $\mathrm{Pb}<\mathrm{Zn}=\mathrm{Cd}$ in 2009 and became $\mathrm{Pb} \sim \mathrm{Cd}<\mathrm{Zn}$ in 2021. This order was relatively different than in others mining contexts (e.g., Obiora et al., 2015) 
Therefore, the long exposure period of the mine wastes was a determining factor as these contamination sources increased with time the Jebel Ressas soil pollution. The progressive TTE loading to the agricultural soil had progressively increased the echological risk and the mobility factors of $\mathrm{Pb}, \mathrm{Zn}$ and $\mathrm{Cd}$ since the deposition of the dumps and until 2021. These dams still pose health risks. Indeed, during around 60 years of exposure, $60 \%$ of the pollutants that were initially in stable forms have been mobilized, and in the last 10 years an additional $6 \%$ of the pollutants have been transformed into labile fractions. Thus, an average of $6 \%$ of the tailings pollutants could be yearly transformed into labile forms. Since the 3 residues actually contained around $15.6 \mathrm{t}$ of $\mathrm{Pb}, 64.4 \mathrm{t}$ of $\mathrm{Zn}$ and $0.4 \mathrm{t}$ of $\mathrm{Cd}$, the annual mobilization of the pollutant stock will be $0.03 \mathrm{t}$ of $\mathrm{Pb}, 0.1 \mathrm{t}$ of $\mathrm{Zn}$ and $0.6 \mathrm{~kg}$ of $\mathrm{Cd}$. By the way, the high TTE mobility of the close soil to the dumps confirmed the contribution of the mobile TTE portions to this site pollution.

\section{Redistribution Index $\left(U_{t s}\right)$ and relative binding intensity $\left(I_{R}\right)$}

Thus, it was important to numerically assess their redistribution and transformation evolution that could be seen from changes in their "equilibrium" parameters (Banin et al. 1990; Han and Banin 1997, 1999; McGrath and Cegarra 1992)

Following the long exposition time of the mine wastes (from 1952 to 2021), the Pb, Zn and Cd incubation highly increased the whole waste values $\left(U_{t s}\right)$ in DII and DIII to reach up to 180. During the two sampled periods (2009 and 2021), the order of the Uts mean values of DII and DIII was $\mathrm{Pb}=142<\mathrm{Zn}=28<\mathrm{Cd}=13$. The three pollutants $U_{t s}$ of DII in 2021 were higher than those of 2009 and with exposure time of the tailings, the three trace elements of the two mine wastes had the same decreasing trend (Fig. 8). The $\mathrm{U}_{\mathrm{ts}}$ ranges of soil $\mathrm{Pb}, \mathrm{Zn}$ and $\mathrm{Cd}$ were 13.20.27 in 2009 and 3.6-0.24 in 2021. The highest soil $U_{t s}$ was of the Pb (3-13) and the less was of the Cd (0.24-0.27) and the pollutants order increase was $\mathrm{Pb}<\mathrm{Zn}$ (Fig. 9).

The $I_{R}$ parameter enables to quantify the relative binding intensity of TTE to the wastes and soil fractions. The relative bending intensity $I_{R}$ range of the three TTE of both tailings was $0.14-0.70$. The $I_{R}$ of $P b$ in DII were higher (0.62 and 0.7) than in DIII (0.5 and 0.56). However, the $\mathrm{Zn} \mathrm{I} \mathrm{I}_{\mathrm{R}}$ values were higher in DIII (0.62 and 0.7) than in DII (0.44 and 0.55). For both sampling periods, the $\mathrm{I}_{\mathrm{R}}$ increasing order of DII was $\mathrm{Pb}>\mathrm{Zn}>\mathrm{Cd}$. However in DIII, a fluctuation of the $I_{R}$ values was observed (Fig. 10). These data showed that the relative binding intensity parameter evolution of TTE in contaminated soils was different from those of the dumps. The mean $I_{R}$ of the loaded $\mathrm{Pb}, \mathrm{Zn}$ and $\mathrm{Cd}$ towards the soil were 5.87, 6.20 and 0.42. When the three TTE logged in soil they increased to be $0.9(\mathrm{~Pb}), 0.7(\mathrm{Zn})$ and $0.6(\mathrm{Cd})$ in 2009. The $\mathrm{I}_{\mathrm{R}}$ of $\mathrm{Pb}$ and $\mathrm{Zn}$ in 2021 decreased to $0.7(\mathrm{~Pb}), 0.4(\mathrm{Zn})$ and of $\mathrm{Cd}$ remained similar (0.6) (Fig. 11).

The TTE redistribution and transformation is affected by three factors that are (i) the distribution of the TTE in the native environment, (ii) the metal loading level, and (iii) the time of TTE addition (Han and Banin 1997). Hence, the TTE redistribution and transformation of whole tailings and soil $\left(U_{t s}\right)$ and their relative bending intensity $\left(I_{R}\right)$ evolution depended on the labile TTE quantities in mine wastes and on their loading level from dumps to the soil, respectively. In the initial tailings and native soil that were at quasi-equilibrate state the $U_{\text {ts }}$ were $\approx 1$. At low and high TTE loading levels, the $U_{\text {ts }}$ of the agricultural soil reached immediately the values around 3 and 25 (Han and Banin 1999), respectively. With time, the whole-soil should reach the equilibrium state and the $U_{t s}$ values will decrease to be around the unity at the low TTE loading level. At the high pollutants level loading, the $U_{\text {ts }}$ level stabilized around 3-4 indicating a return to a distribution pattern similar to the initial soil (Han and Banin 1999). 
In initial tailings, the TTE were mainly bounded to residual fractions. From the first waste deposition period to 2009 , the $U_{\text {ts }}$ values were widely higher that 25 (Han and Banin 1999), particularly of Pb. These data showed that the mobile TTE quantities remained very high (far from the equilibrium state). The very high $U_{t s}$ values increase of $\mathrm{Pb}$ were mainly due to the residence of a high TTE quantities in the Fe and Mn oxide and organically and sulfur fractions (Fig. 12). Compared with $\mathrm{Pb}$, the found decrease of the $\mathrm{U}_{\mathrm{ts}}$ (moderately low) of $\mathrm{Zn}$ was because this element was essentially transferred from the residual to organically and sulfur fractions (Fig. 13). However, the low $\mathrm{Cd}-\mathrm{U}_{\mathrm{ts}}$ were due to the low $\mathrm{Cd}$ concentrations and the differences of the TTE distribution in the dumps (Fig. 14). Therefore, the $U_{t s}$ intensity changes were closely related to the increase of the mobile $\mathrm{Pb}, \mathrm{Zn}$ and $\mathrm{Cd}$ quantities. As a high stable TTE percentages were transferred from 1952 to 2021 to the exchangeable and carbonate, Fe and Mn oxides and organic fractions, the tailings $U_{t s}$ acquired larger values (from 80 to 180). These labile toxic elements moved from the tailings towards the native soil where the initial TTE were also in equilibrium state. The added quantities of the toxic elements perturbed the soil "equilibrium" parameters. Indeed, the mean $U_{\text {ts }}$ values of $\mathrm{Pb}$ and $\mathrm{Zn}$ (major pollutants) increased from the initial values (around one) to around 3.4 in 2009 and 12 in 2021.

In DII, the Cd had the lowest bending intensity that explained by the high pollutants transfer rate to the soil. While $\mathrm{Pb}$ was the most toxic trace that bounded to sediments meaning that it was the most stable in the dumps. However, $\mathrm{Pb}$ in DIII had the lowest $\mathrm{I}_{\mathrm{R}}$ and those of $\mathrm{Zn}$ and $\mathrm{Cd}$ were higher and comparable meaning that the $\mathrm{Pb}$ loading rate was higher than those of $\mathrm{Zn}$ and $\mathrm{Cd}$. Thus, the decreasing impact health order of the two dumps pollutants was $\mathrm{Cd}>\mathrm{Zn}>\mathrm{Pb}$. This $\mathrm{I}_{\mathrm{R}}$ difference that depended on the transfer degree of TTE was essentially due to a difference of the mineralogical and geochemical characteristics of both dumps (Johnson et al. 2000, Singh et al. 2010; Khan et al. 2008). Indeed, the sphalerite and galena were the main minerals that contained the $\mathrm{Pb}$ and $\mathrm{Zn}$ while the $\mathrm{Zn}$ from DIII tailings was released from hemimorphite $\left(\mathrm{ZnCO}_{3}\right)$. Between 1952 and 2009 , the long residence time of pollutants in the soil increased their $I_{R}$ meaning that some proportions of the mobile forms of $\mathrm{Pb}, \mathrm{Zn}$ and $\mathrm{Cd}$ bounded to residual soil fractions. After that (2009-2021), the increase of the pollutants loading level towards the soil largely decreased the soil $I_{R}$. This decline was higher for $\mathrm{Zn}(0.3)$ than for $\mathrm{Pb}(0.2)$. While the $\mathrm{I}_{\mathrm{R}}$ of $\mathrm{Cd}$ remained unchanged.

Hence, the initial TTE quantities in Jbel Ressas tailings and soil had any health impact. From the 1952 to 2009 , the $U_{t s}$ increase and the $I_{R}$ decrease values of tailings and soil of the TTE widely increased their potential risks. During the last 10 years, the of change rates of the $U_{t s}$ and $I_{R}$ of the $P b, Z n$ and $C d$ had further increased their health risks.

Therefore, the evaluation of the historical evolution of the tailings and soil in TTE contents, mobility's and stabilities has allowed drawing up a complete balance sheet indicating that these dykes are always a source of risk. Thus, this complete diagnosis insuited the decision makers to suggest an appropriate plan for the development of the dikes and the polluted soil.

\section{Conclusion}

The overall historical assessment of the mine wastes of Jbel Ressas showed that the TTE quantities already migrated from the tailings towards the surrounding areas, remaining and retained by the soil and their distributions were evaluated. The of the TTE mobility evolution of in the whole site, the ecological indexes and the

Page $12 / 26$ 
impact of the still available TTE quantities and their danger level to the agricultural soils were also considered. The quantities of $\mathrm{Pb}, \mathrm{Zn}$ and $\mathrm{Cd}$ in the initial wastes were $46640 \mathrm{t}, 134780 \mathrm{t}$ and $1150 \mathrm{t}$. The remained quantities in the wastes are $15.6 \mathrm{t}$ of $\mathrm{Pb}, 64.2 \mathrm{t}$ de $\mathrm{Zn}$ and $0.4 \mathrm{t}$ de $\mathrm{Cd}$ that presented a worrying environmental hazard. During around 60 years $50 \%$ of the three traces were transferred to labile forms and during the last 10 years around $22.6 \%$. Hence, the migration speed of pollutants was accelerated with the the dumps time exposition. Thus, the risk of these pollutant sources is still high. Of the TTE that migrated from the tailings, only $6.1,4.8$, and $4.1 \%$ of $\mathrm{Pb}, \mathrm{Zn}$, and $\mathrm{Cd}$, respectively, were retained by the top two meters of soil of the investigated site where the potential ecological risk (Eri.) was high. Since 1952 and until 2009 around 60\% of the tailings TTE have been mobilized and from 2009 to 2021 around 6\%. The high mobility of the TTE of soil closes to the dumps and the crystallization of the impermeable carbonate crust that covered the tailings surface, confirmed the contribution of mobile soil TTE to the site pollution. Therefore, the remained TTE quantities in the tailings and their future redistribution and transformations and risks will worry.

The TTE whole-soil removal $\left(U_{t s}\right)$ and the relative binding intensity index $\left(I_{R}\right)$ that describe the evolution of the environment equilibrium state, were $\approx 1$ in Jbel Ressas initial tailings and soil meanings they were stable and without any health risk. From 1952 to 2021, the $\mathrm{U}_{\text {ts }}$ increase and IR decrease values of tailings and soil $\mathrm{Pb}, \mathrm{Zn}$ and $\mathrm{Cd}$ marked the widely the increase of their instability and potential risks, particularly during the last 10 years.

Therefore, the evaluation of the historical evolution of the tailings and soil TTE contents and their motilities and stability allowed drawing up a complete balance sheet. as these source pollutions continued to be a of serious health risk, the suggestion of an appropriate management plan by decision makers urgent.

\section{Declarations}

\section{Conflicts of interest}

The authors declare no conflicts of interest

\section{Acknowledgements}

We would like thank the Tunisian Ministry of High Education and Scientific Research's. We are grateful to our native English speaker for his text revision.

\section{References}

1. Allen HE (1997) Importance of speciation of metals in natural waters and soils to risk assessment. Report of international workshop on risk assessment of metals and their inorganic compounds. International Council on Metals and the Environment. Ottawa pp 141-157

2. Acosta JA, Faz A, Martínez-Martínez S, Zornoza R, Carmona DM, Kabas S (2011) Multivariate statistical and GIS-based approach to evaluate heavy metals behavior in mine sites for future reclamation. J Geochem Explor 109:8-17

3. Abrahim GMS, Parker RJ, Nichol SL (2007) Distribution and assessment of sediment toxicity in tamaki estuary, Auckland, New Zealand. Environ Geol 52:1315-1323 
4. Banin A, Gerstl Z, Fine P, Metzger Z, Newrzella D (1990) Minimizing Soil Contamination Through Control of Sludge Transformations in Soil, Joint German-Research project, Final Report. No. of Project: Wt 8687/458

5. Bergaya E, Vayer M (1997) CEC of clays: Measurement by adsorption of a copper ethylenediamine complex. Appl Clay Sci 12:275-280

6. Bowen HJM (1979) Environmental chemistry of the elements. Academic Press, London

7. Boussen S, Soubrand M, Bril H, Ourfelli K, Abdeljaouad S (2013) Transfer of lead, Zinc and cadmium from mine tailings to wheat (Triticumaestivum) in carbonated Mediterranean (North Tunisia) soils. Geoderma 192:227-236

8. Conesa HM, Hector M, Faz A (2011) Metal uptake by spontaneous vegetation in acidic mine tailings from a semiarid area in south spain: Implications for revegetation and land management. Water Air Soil pollut 215:221-227

9. Camden-smith BPC, Tutu H (2014) Geochemical modeling of the evolution and fate of metal pollutants arising from an abandoned gold mine tailings facility in johannesburg. Water Sci Technol 69:1108-1114

10. Davidson GM, Duncan AL, Littlejohn D, Ure AM, Garden LM (1998) A critical avaluation of the three-stage BCR sequential extraction procedure to assess the potential mobility and toxicity of heavy metals in individually contaminated land. Anal Chim acta 363:45-55

11. Dean JR (2007) Bioavailability, bioaccessibility and mobility of environmental contaminants.Analytical techniques in the Sciences. Wiley Chichester 292p

12. Elouear Z, Bouhamed F, Boujelben N, Bouzid J (2016) Assessment of toxic metals dispersed from improperly disposed tailing, Jebel Ressas mine, NE Tunisia. Environ Earth Sci 75:254

13. Fengxia GU, Wenbao $L$ (2010) Application of remote sensing and GIS to the assessment of riparian zone for environmental restoration in agricultural watersheds. Geo Spat Inf Sci 13:263-268

14. Favas PJ, Pratas J, Gomes MEP, Cala V (2011) Selective chemical extraction of heavy metals in tailings and soils contaminated by mining activity: Environmental implications. J Geochem Explor 111:160-171

15. Ghorbel Ben Abid M (2012) Contamination métallique issue des déchets de l'ancien site minier de Jebel Ressas: modélisation des mécanismes de transfert et conception de cartes d'aléa postmine dans un contexte carbonaté et sous un climat semi-aride. Evaluation du risque pour la santé humaine (Doctoral dissertation Université Toulouse III -Paul Sabatier), 233p

16. Hakanson L (1980) Ecological risk index for aquatic pollution control. A sedimentological approach. Water Res 14:975-1001

17. Sahraoui H, Hachicha M (2016) Determination of trace elements in mine soil samples using portable X-ray fluorescence spectrometer: A comparative study with ICP-OES. Eng Appl Sci Res 43:162-165

18. Han FX, Banin A (1997) Long-term transformations and redistribution of potentially toxic heavy metals in arid-zone soils incubated: I. Under saturated conditions. Water Air Soil Pollut 95:399-423

19. Han FX, Banin A (1999) Long- therm transformation and distribution of potentially toxic heavy metals in aridzone soils: Il incubation at field capacity moisture content. Water Air Soil Pollut 114:221-250

20. Han FX, Banin A (1999) Long-term transformation and redistribution of potentially toxic heavy metals in aridzone soils: II. Incubation at the field capacity moisture content. Water Air Soil Pollut 114:221-250

21. Johnson RH, Blowes DW, Robertson WD, Jambor JL (2000) The hydrogeochemistry of the nickel rim mine tailings impoundment, Sudbury, Ontario. J Contam Hydro 41:49-80

Page $14 / 26$ 
22. Kabata-Pendias A (1993) Behavioural properties of trace metals in soils. Appl Geochem 2:3-9

23. Kabata-Pendias A (2004) Soil-plant transfer of trace elements an environmental issue. Geoderma 122:143149

24. Khan S, Cao Q, Zheng YM, Huang YZ, Zhu YG (2008) Health risks of heavy metals in contaminated soils and food crops irrigated with wastewater in Beijing, China. Environ Pollut 152:686-692

25. Müller G (1969) Index of geo-accumulation in the sediments of the Rhine River. GeoJournal 2:108-118

26. Martínez-Fernández M, Barciela-Alonso MC, Moreda-Piñeiro A, Bermejo-Barrera P (2011) Matrix solid phase dispersion-assisted BCR sequential extraction method for metal partitioning in surface estuarine sediments. Talanta 83:840-849

27. Maiz I, Arambarri I, Garcia R, Millan E (2000) Evaluation of heavy metal availability in polluted soils by two sequential extraction procedures using factor analysis. Environ Pollut 110:3-9

28. McGrath SP, Cegarra J (1992) Chemical extractability of heavy metals during and after long-term applications of sewage sludge to soil. J Soil Sci 43:313-321

29. Navarro MC, Perez-Sirvent C, Martinez-Sanchez MJ, Vidal J, Tovar PJ, Bech J (2008) Abandoned mine sites as a source of contamination by heavy metals: a case study in a semi-arid zone. J Geochem Explor 96:183193

30. INM (2020) annuaire de Institut National de Metéo de Tunisie

31. Obiora SC, Chukwu A, Davies TC (2015) Heavy metals and health risk assessment of arable soils and food crops around $\mathrm{Pb}-\mathrm{Zn}$ mining localities in Enyigba, southeastern Nigeria. J African Earth Sci 116:182-189

32. Quevauviller P (1998) Operationally defined extraction procedures for soil and sediment analysis I. Standardization. TrAC Trends in Anal Chem 17:289-298

33. Rao CRM, Sahuquillo A, Sanchez JL (2008) A review of the different methods applied in environmental extraction of trace elements in soils and related materials. Water Air soil pollut 189:291-333

34. Sliti N, Abdelkrim C, Ayed L (2019) Assessment of tailings stability and soil contamination of Kef Ettout (NW Tunisia) abandoned mine. Arab J Geosci 12:73

35. Singh A, Sharma RK, Agrawal M, Marshall FM (2010) Health risk assessment of heavy metals via dietary intake of foodstuffs from the wastewater irrigated site of a dry tropical area of India. Food Chem Toxicol 48:611-619

36. Sainfeld P (1952) Les gîtes plombo-zincifères de Tunisie. Ann Min Géol Tunis 9:1-285

37. Souissi R, Souissi F, Ghorbel M, Munoz M, Courjault-Radé P (2014) Mobility of Pb, Zn and Cd in a soil developed on a carbonated bedrock in à semi-arid climate and contaminated by $\mathrm{Pb}-\mathrm{Zn}$ tailing, Jebel Ressas (NE Tunisia). Environ Earth Sci 73:3501-3512

38. Salomons W, Forstner U (1984) Metals in estuaries and coastal environments. Metals in the hydrocycle. Springer, Berlin Heidelberg, pp 212-257

39. Tessier A, Compbell PGC, Bison M (1979) Sequential extraction procedure for the speciation of articulate trace metals. anal chem 51:844-850

40. Tembo BD, Sichilongo K, Cernak J (2006) Distribution of copper, lead, Cadmium and zinc concentrations in soils around Kabwe town in Zambia. Chemosphere 63:497-501

41. Ure AM, Quevauviller PH, Muntau H, Griepink B (1993) Speciation of heavy metals in soils and sediments. An account of the improvement and harmonization of extraction techniques undertaken under the auspices of

Page $15 / 26$ 
the BCR of the Commission of the European Communities. International J Environ Anal Chem 51:135-151

42. Van der Marei HW (1966) Quantitative analysis of clay minerals and their admixtures. Contrib Mineral Petrol 12:96-138

43. Walkley A, Black IA (1934) An examination of the Degtjareff method for determining soil organique matter and a proposed modification of the chromic acid titration method. Soil Sci 37:29-38

44. Zornoza R, Faz A, Carmona DM, Kabas S, Mart'ınez-Mart'ınez S, Acosta JA (2012) Plant cover and soil biochemical properties in a mine tailing pond five years after application of marble wastes and organic amendments. Pedosphere 22(1):22-32

\section{Tables}

Table 1 Used extraction procedures

\begin{tabular}{|lll|}
\hline Fractions & Methods & References \\
\hline $\begin{array}{l}\text { F1: Exchangeable and carbonate } \\
\text { bound Fraction }\end{array}$ & $0.11 \mathrm{~mol} \mathrm{~L}^{-1}$ of $\mathrm{AcOH}$ & $\begin{array}{l}\text { Davidson et al. (1994); Ure } \\
\text { et al. (1993) }\end{array}$ \\
\hline $\begin{array}{l}\text { F2: Fe and Mn oxide bound } \\
\text { Fraction }\end{array}$ & $\mathrm{NH}_{2} \mathrm{OH}-\mathrm{HCl}\left(0.1 \mathrm{~mol} \mathrm{~L}^{-1}, \mathrm{pH} 2\right.$ \\
$\begin{array}{l}\mathrm{F} 3 \text { (Organically and sulfur bound } \\
\text { Fraction.) }\end{array}$ & $\begin{array}{l}\mathrm{H}_{2} \mathrm{O}_{2}\left(8.8 \mathrm{~mol} \mathrm{~L}^{-1}, \mathrm{pH} 3.2\right) \text { and AcONH4 } \\
\left(1 \mathrm{~mol} \mathrm{~L}^{-1}, \mathrm{pH} 2\right.\end{array}$ \\
\hline F4: Residual Fraction) & Digestion $\left(\mathrm{HCl}-\mathrm{HNO}_{3}\right)+\mathrm{HF}\left(150{ }^{\circ} \mathrm{C}-2\right.$ \\
\hline
\end{tabular}

Table 2 Physicochemical proprieties of actual tailing wastes

\begin{tabular}{|llllll|}
\hline & $\mathrm{pH}$ & $\begin{array}{l}\mathrm{EC} \\
\left(\mathrm{mScm}{ }^{-1}\right)\end{array}$ & $\begin{array}{l}\text { CEC } \\
\left(\mathrm{meq} 100 \mathrm{~g}^{-1}\right)\end{array}$ & $\begin{array}{l}\text { TOC } \\
\left(\mathrm{gkg}^{-1}\right)\end{array}$ & $\begin{array}{l}\text { Phy. } \\
(\%)\end{array}$ \\
\hline Mean & 7.6 & 2.3 & 16.7 & 2.1 & 15 \\
\hline SD & 0.2 & 2.7 & 3.2 & 0.45 & 2 \\
\hline Min & 7.3 & 0.2 & 12.3 & 1.2 & 14 \\
\hline Max & 7.9 & 17.5 & 21.7 & 3.28 & 16 \\
\hline $\mathrm{N}$ & 102 & 109 & 76 & 109 & 121 \\
\hline
\end{tabular}

Phy.: Phyllosilicate ; N: samples number, Max: maximum; Min: minimum; SD: standard deviation; TOC: total organic carbon.

Table 3 Physicochemical properties of the agricultural soils in 2009 and 2021 


\begin{tabular}{|c|c|c|c|c|c|c|c|}
\hline & $\mathrm{PH}$ & $\begin{array}{l}\text { EC } \\
\left(\mu \mathrm{cm}^{-1}\right)\end{array}$ & $\begin{array}{l}\text { CEC } \\
\left(\text { meq } 100 g^{-1}\right)\end{array}$ & $\mathrm{OM}(\%)$ & $\mathrm{CaCO}_{3}(\%)$ & Sand (\%) & Silt (\%) \\
\hline Min & 6.70 & 101.7 & 35.0 & 0.3 & 55.0 & 23.0 & 15.0 \\
\hline Max & 9.13 & 5900.0 & 55.0 & 2.9 & 100.0 & 80.9 & 66.4 \\
\hline Mean & 7.52 & 1647.9 & 42.2 & 1.6 & 49.0 & 51.3 & 37.0 \\
\hline SD & 0.73 & 1538.4 & 6.1 & 0.7 & 26.9 & 15.5 & 13.9 \\
\hline
\end{tabular}

Table 4 The evolution of the statistic Pb, Zn, Cd concentrations of the soil

\begin{tabular}{|llllll|}
\hline Year & & $\begin{array}{l}\mathrm{Pb} \\
\left(\mathrm{mgkg}^{-1}\right)\end{array}$ & $\begin{array}{l}\mathrm{Zn} \\
\left(\mathrm{mgkg}^{-1}\right)\end{array}$ & $\begin{array}{l}\mathrm{Cd} \\
\left(\mathrm{mgkg}^{-1}\right)\end{array}$ & $\begin{array}{l}\text { Total } \\
\text { TTE }\end{array}$ \\
\hline Initial* & min & 27 & 55 & 0.3 & \\
\hline & max & 85 & 121 & 1.1 & \\
\hline & Mean & 55 & 101 & 0.5 & 156.5 \\
\hline & SD & 10 & 23 & 0.3 & \\
\hline & min & 181 & 659 & 9 & \\
\hline & max & 52396 & 31229 & 139 & \\
\hline & Mean & 10798 & 8600 & 98 & 19496 \\
\hline & SD & 1299 & 1054 & 21 & \\
\hline & min & 3130 & 12140 & 24 & \\
\hline & max & 28470 & 28600 & 170 & \\
\hline & Mean & 12128 & 18715 & 67 & 30910 \\
\hline & SD & 9837 & 8120 & 62 & \\
\hline
\end{tabular}

*: Background, TTE: toxic trace elements.

Table 5 The evolution of the average toxic trace elements concentrations of the different sectors of the agricultural soil in 2009 and 2021 


\begin{tabular}{|lllllll|}
\hline & 2009 & \multicolumn{5}{c|}{2021} \\
\hline & $\mathrm{Pb}$ & $\mathrm{Zn}$ & $\mathrm{Cd}$ & $\mathrm{Pb}$ & $\mathrm{Zn}$ & $\mathrm{Cd}$ \\
\hline Sector 1 & 2148 & 13053 & 81 & 3130 & 28600 & 42 \\
\hline Sector 2 & 6757 & 6997 & 113 & 7554 & 13520 & 82 \\
\hline tor 3 & 25054 & 12495 & 167 & 28470 & 26513 & 152 \\
\hline Sector 4 & 7604 & 5111 & 71 & 8074 & 12140 & 36 \\
\hline Sector 5 & 12427 & 5347 & 58 & 13414 & 12800 & 24 \\
\hline
\end{tabular}

Table 6 The affinity orders of Pb, Zn and Cd of the different sectors in 2009 and 2021

\begin{tabular}{lllllll} 
& 2009 & & \multicolumn{2}{c}{2021} \\
\hline & $\mathrm{Pb}$ & $\mathrm{Zn}$ & $\mathrm{Cd}$ & $\mathrm{Pb}$ & $\mathrm{Zn}$ & $\mathrm{Cd}$ \\
\hline Sector1 & $\mathrm{F} 4>\mathrm{F} 2>\mathrm{F} 3>\mathrm{F} 1$ & $\mathrm{~F} 4>\mathrm{F} 3>\mathrm{F} 2>\mathrm{F} 1$ & $\mathrm{~F} 4>\mathrm{F} 2>\mathrm{F} 3>\mathrm{F} 1$ & $\mathrm{~F} 3>\mathrm{F} 2>\mathrm{F} 4>\mathrm{F} 1$ & $\mathrm{~F} 4>\mathrm{F} 1>\mathrm{F} 3>\mathrm{F} 2$ & $\mathrm{~F} 3>\mathrm{F} 2>\mathrm{F} 4>\mathrm{F} 1$ \\
\hline Sector2 & $\mathrm{F} 4>\mathrm{F} 2>\mathrm{F} 3>\mathrm{F} 1$ & $\mathrm{~F} 4>\mathrm{F} 3>\mathrm{F} 2>\mathrm{F} 1$ & $\mathrm{~F} 3>\mathrm{F} 2>\mathrm{F} 1>\mathrm{F} 3$ & $\mathrm{~F} 3>\mathrm{F} 4>\mathrm{F} 2>\mathrm{F} 1$ & $\mathrm{~F} 3>\mathrm{F} 2>\mathrm{F} 1>\mathrm{F} 4$ & $\mathrm{~F} 3>\mathrm{F} 4>\mathrm{F} 2>\mathrm{F} 1$ \\
\hline Sector3 & $\mathrm{F} 4>\mathrm{F} 2>\mathrm{F} 3>\mathrm{F} 1$ & $\mathrm{~F} 4>\mathrm{F} 3>\mathrm{F} 2>\mathrm{F} 1$ & $\mathrm{~F} 4>\mathrm{F} 1>\mathrm{F} 2>\mathrm{F} 3$ & $\mathrm{~F} 4>\mathrm{F} 3>\mathrm{F} 2>\mathrm{F} 1$ & $\mathrm{~F} 1>\mathrm{F} 2>\mathrm{F} 3>\mathrm{F} 4$ & $\mathrm{~F} 4>\mathrm{F} 3>\mathrm{F} 2>\mathrm{F} 1$ \\
\hline Sector4 & $\mathrm{F} 4>\mathrm{F} 2>\mathrm{F} 3>\mathrm{F} 1$ & $\mathrm{~F} 4>\mathrm{F} 3>\mathrm{F} 2>\mathrm{F} 1$ & $\mathrm{~F} 4>\mathrm{F} 2>\mathrm{F} 3>\mathrm{F} 1$ & $\mathrm{~F} 4>\mathrm{F} 2>\mathrm{F} 3>\mathrm{F} 1$ & $\mathrm{~F} 1>\mathrm{F} 3>\mathrm{F} 2>\mathrm{F} 4$ & $\mathrm{~F} 4>\mathrm{F} 2>\mathrm{F} 1>\mathrm{F} 3$ \\
\hline Sector5 & $\mathrm{F} 4>\mathrm{F} 3>\mathrm{F} 2>\mathrm{F} 1$ & $\mathrm{~F} 4>\mathrm{F} 3>\mathrm{F} 2>\mathrm{F} 1$ & $\mathrm{~F} 4>\mathrm{F} 3>\mathrm{F} 1>\mathrm{F} 2$ & $\mathrm{~F} 4>\mathrm{F} 2=\mathrm{F} 3>\mathrm{F} 1$ & $\mathrm{~F} 2>\mathrm{F} 4>\mathrm{F} 3>\mathrm{F} 1$ & $\mathrm{~F} 4>\mathrm{F} 2=\mathrm{F} 3>\mathrm{F} 1$
\end{tabular}

\section{Figures}




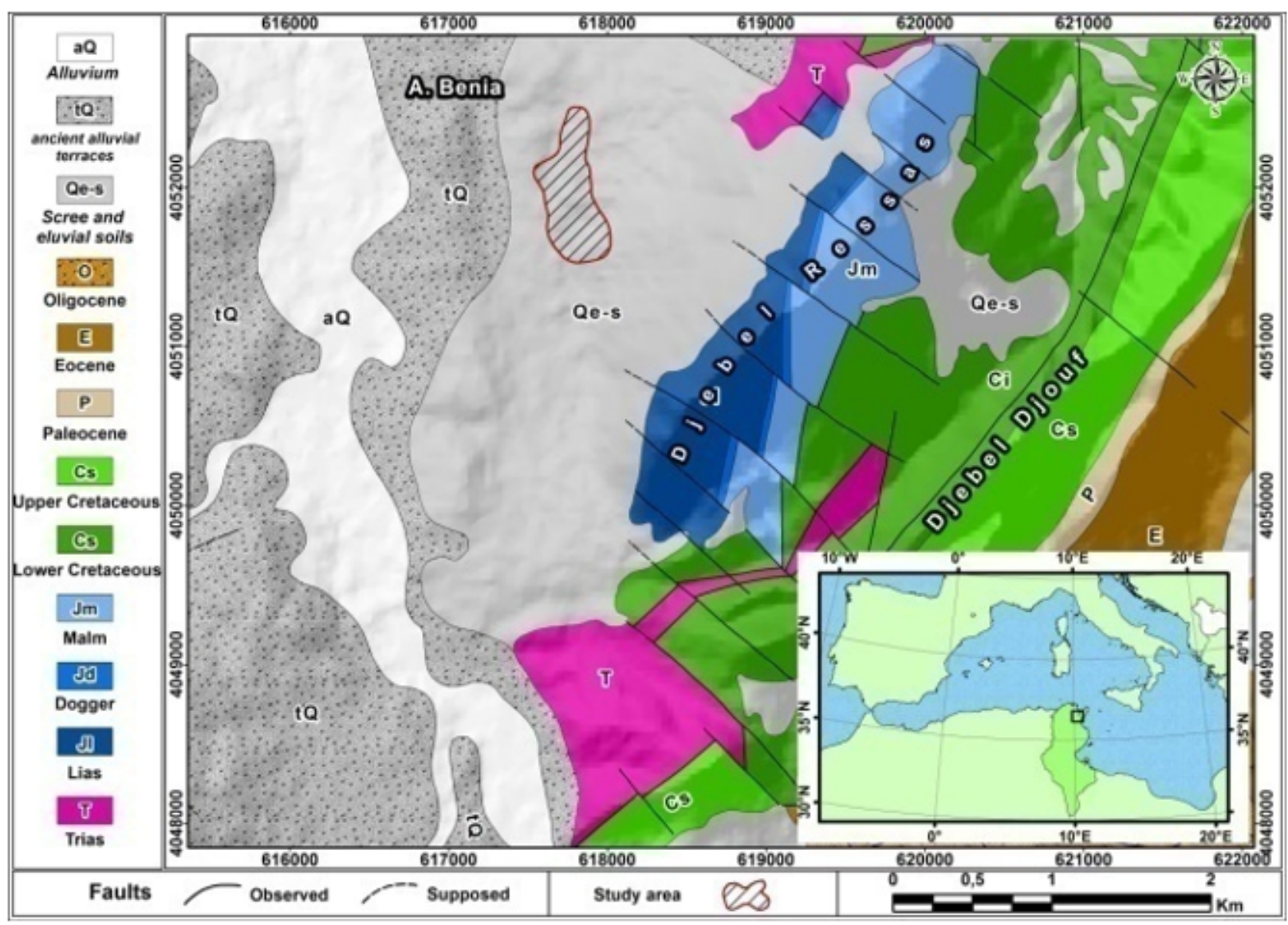

Figure 1

Geological map of the Jebel Ressas area and location of studied area 


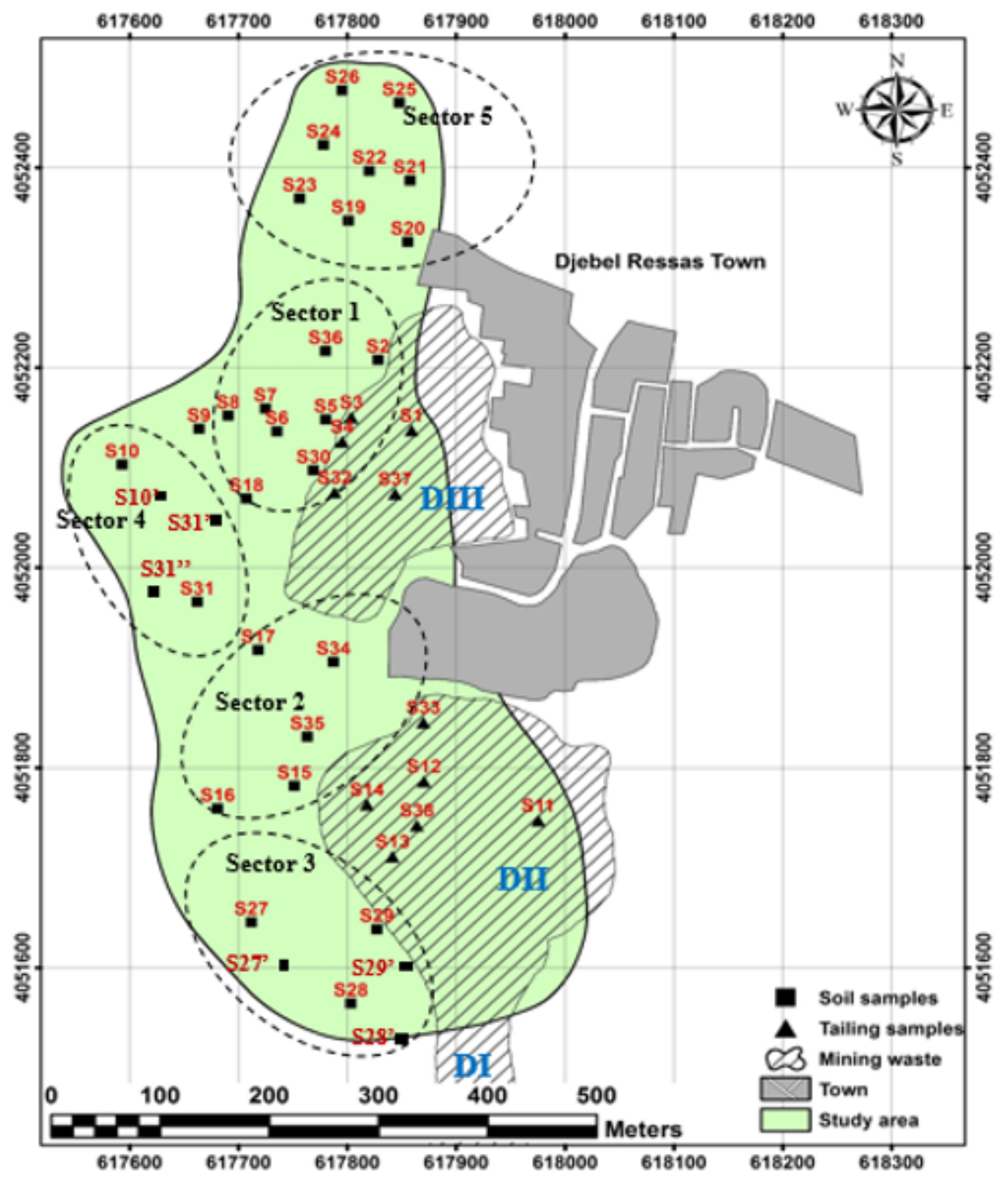

Figure 2

Jbel Ressas agricultural soil map with tailings (DI, DII and DIII) and sampled plots localizations

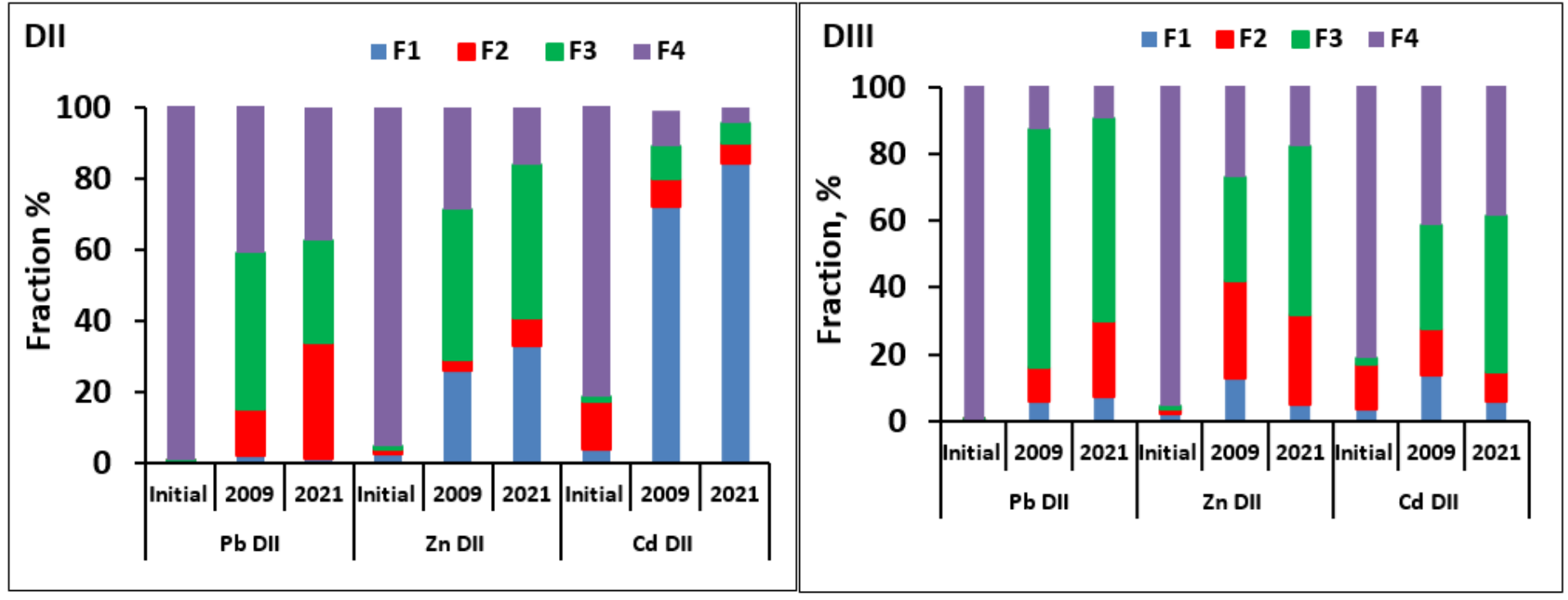


Figure 3

Evolution of toxic trace elements bounded to the Exchangeable (F1), oxides (F2), organic matter (F3) and residual (F4) fractions of DII and DIII sediments

F1: Exchangeable; F2: reductibe; F3: oxidizable; F4: residual; TTE: toxic trace elements

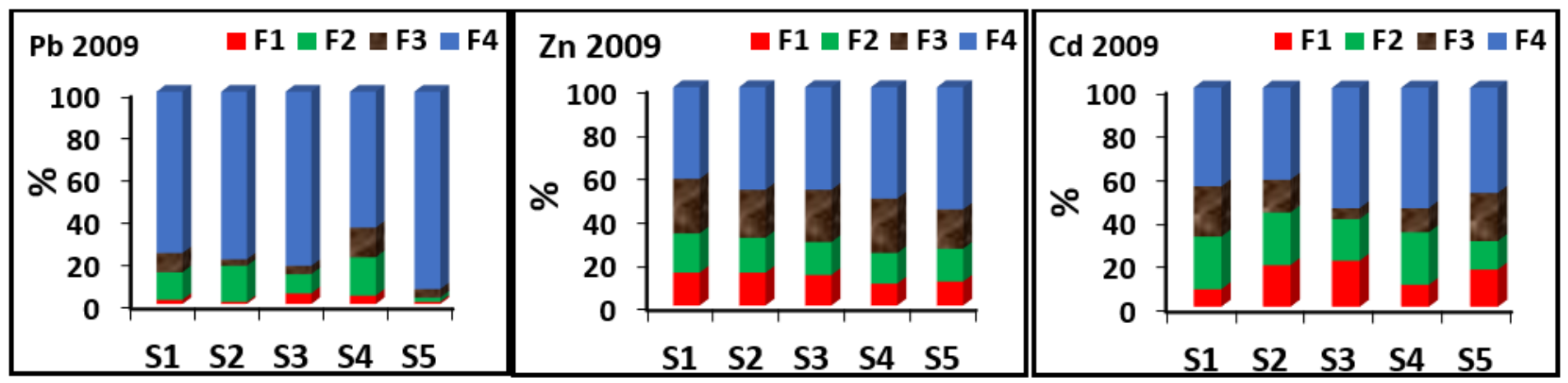

Figure 4

Percentages of the $\mathrm{Pb}, \mathrm{Zn}$ and $\mathrm{Cd}$ in the five soil sectors that bounded to the for soil fractions in 2009

F1: Exchangeable; F2: reductibe; F3: oxidizable; F4: residual; TTE: toxic trace elements
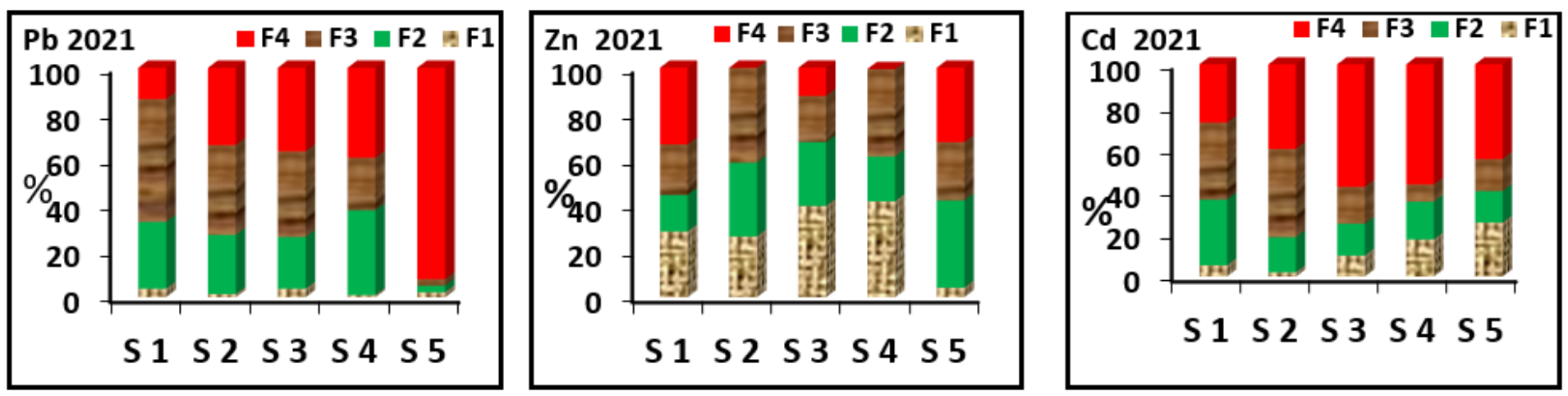

Figure 5

Percentages of $\mathrm{Pb}, \mathrm{Zn}$ and $\mathrm{Cd}$ in the five soil sectors bounded to the for soil fractions in 2021

F1: Exchangeable; F2: reductibe; F3: oxidizable; F4: residual; TTE: toxic trace elements

Figure 6 
Evolution of the toxic trace elements mobility in 2009 and 2021

F1: Exchangeable; F2: reductibe; F3: oxidizable; F4: residual; TTE: toxic trace elements

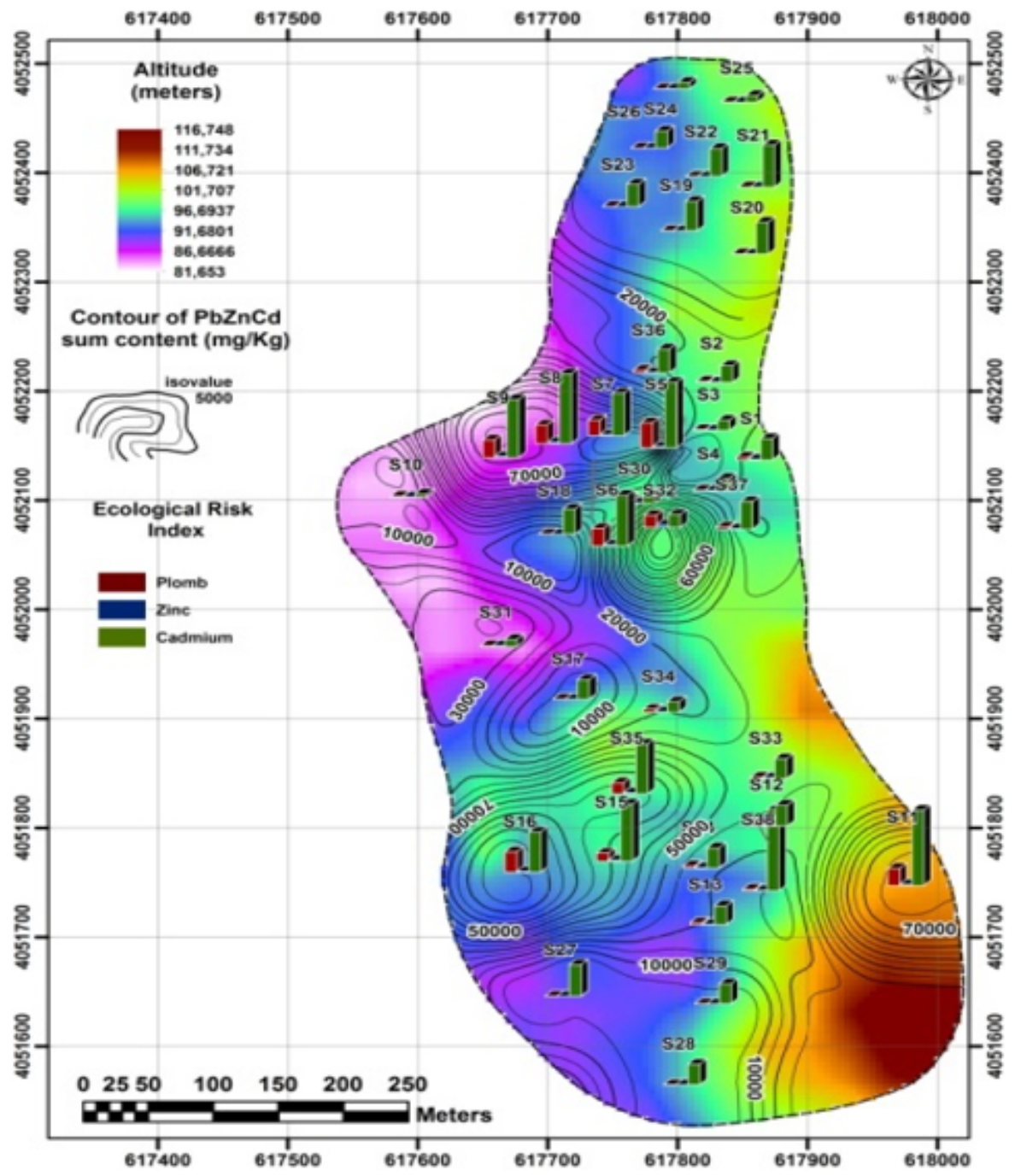

Figure 7

Distribution map of Ecological risk factor $\left(\mathrm{Er}^{\mathrm{i}}\right)$ in agricultural soil of Jebel Ressas 


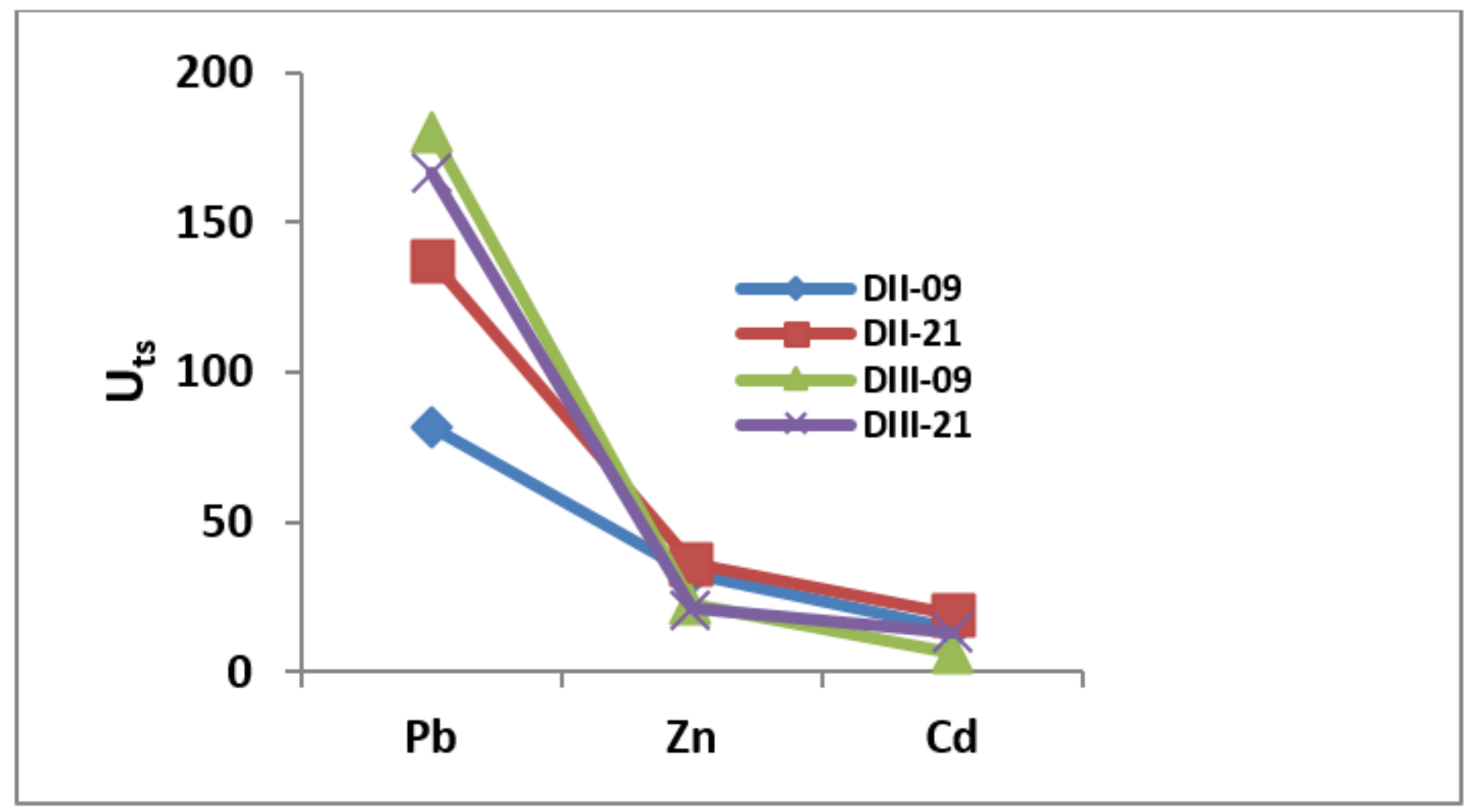

Figure 8

The long-term evolution of equilibrium "parameter $\left(\mathrm{U}_{\mathrm{ts}}\right)$ of the $\mathrm{Pb}, \mathrm{Zn}$ and $\mathrm{Cd}$ in the whole dumps

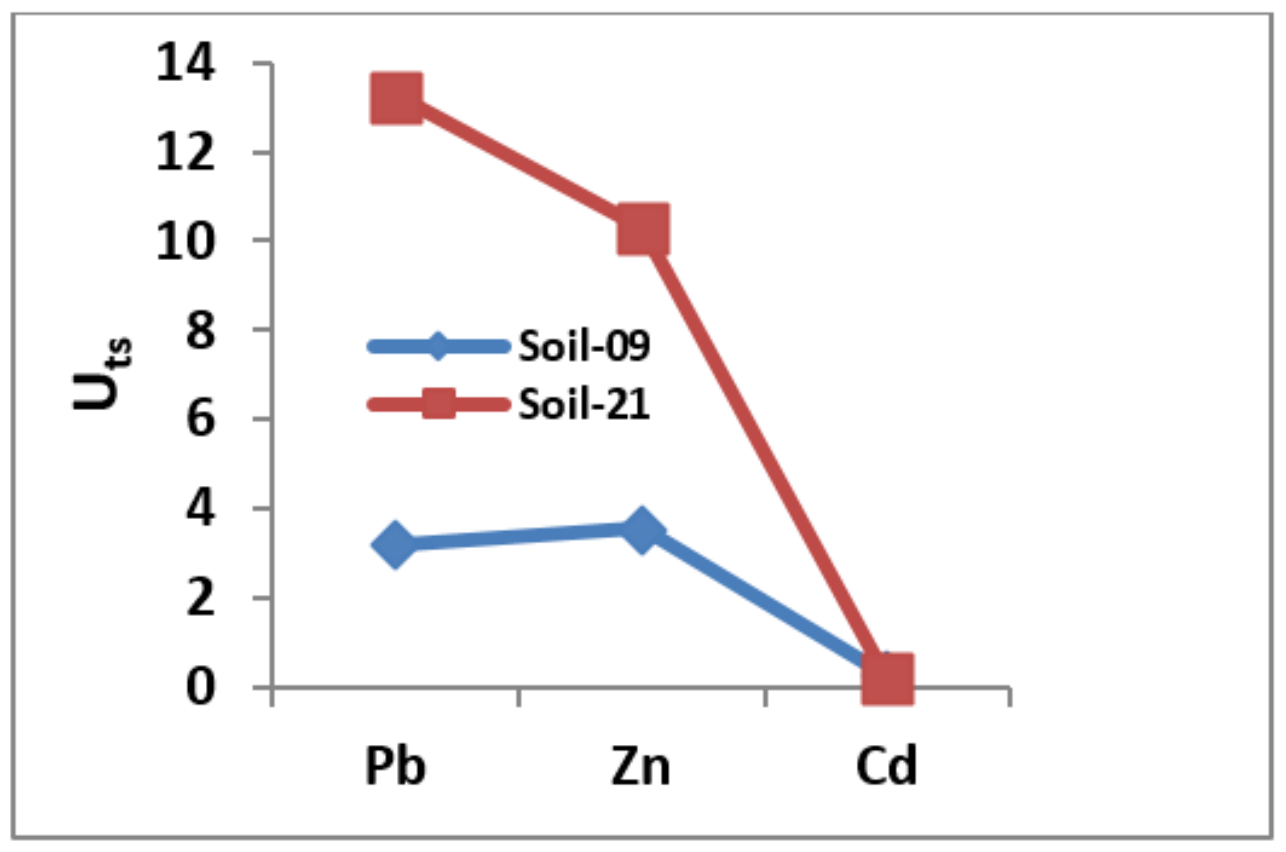

\section{Figure 9}

The long-term evolution of equilibrium" parameter $\left(\mathrm{U}_{\mathrm{ts}}\right)$ of the $\mathrm{Pb}, \mathrm{Zn}$ and $\mathrm{Cd}$ in the whole soil 


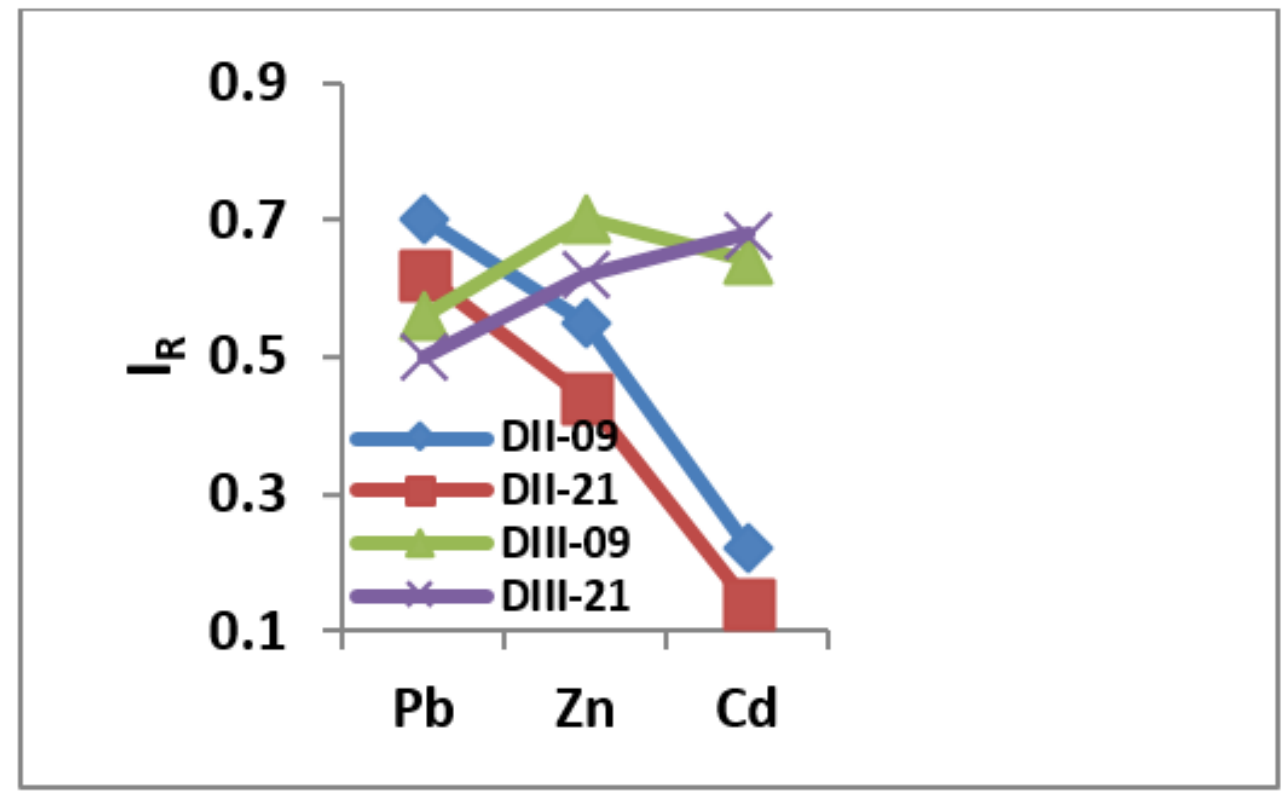

Figure 10

The $\mathrm{Pb}, \mathrm{Zn}$ and $\mathrm{Cd}$ reduced partition index, $\mathrm{I}_{\mathrm{R}}$, evolution of the two dumps

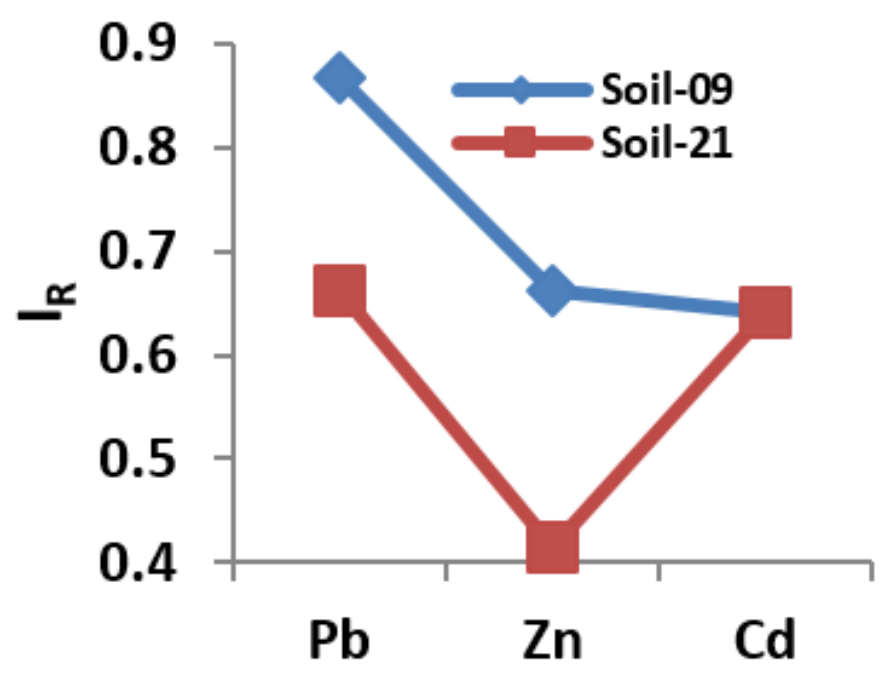

Figure 11

The $\mathrm{Pb}, \mathrm{Zn}$ and $\mathrm{Cd}$ reduced partition index, $\mathrm{I}_{\mathrm{R}}$, evolution of agricultural soil 


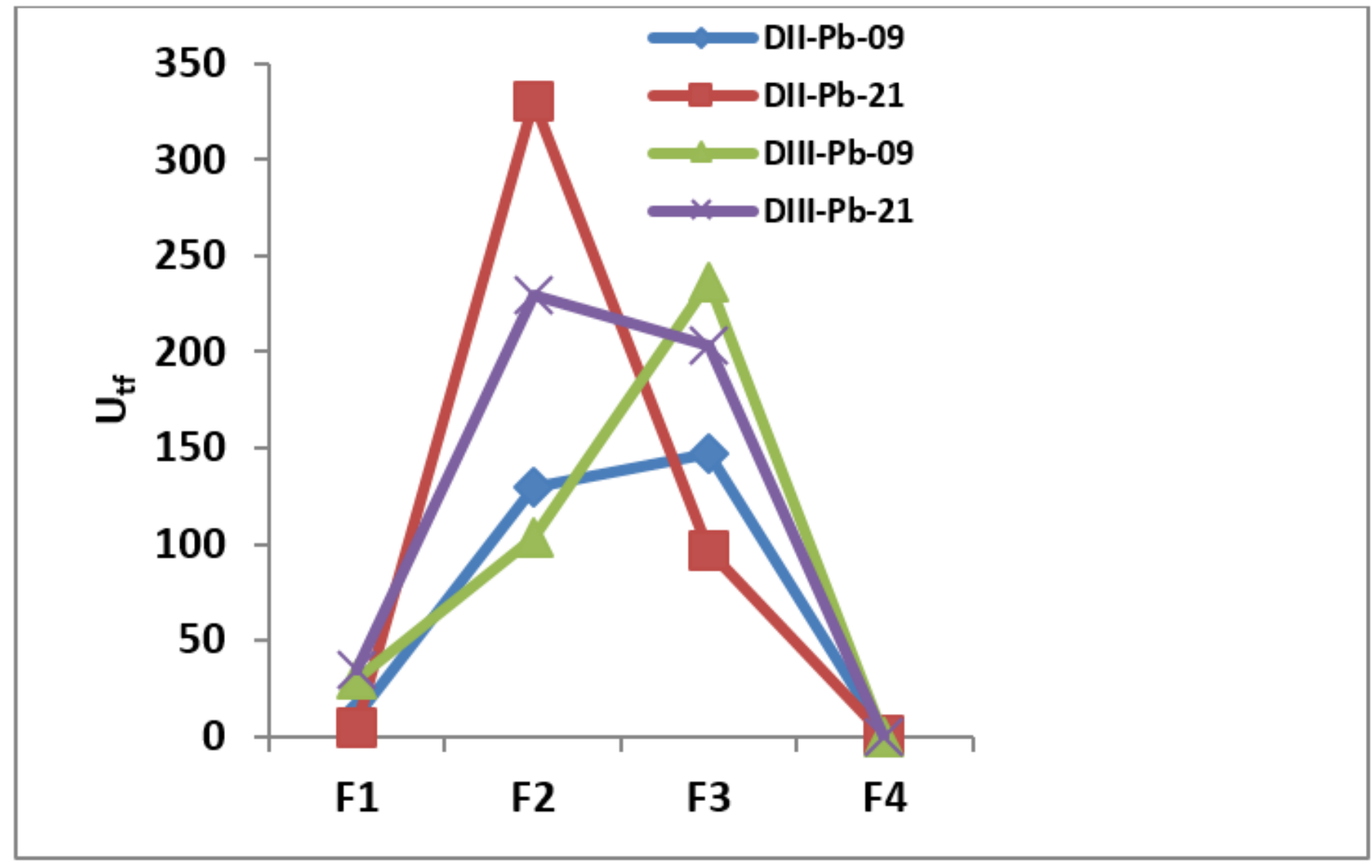

Figure 12

The long-term evolution of the $\mathrm{Pb}$ transformations-distribution (fractional contents $\mathrm{U}_{\mathrm{tf}}$ ) in the two dumps

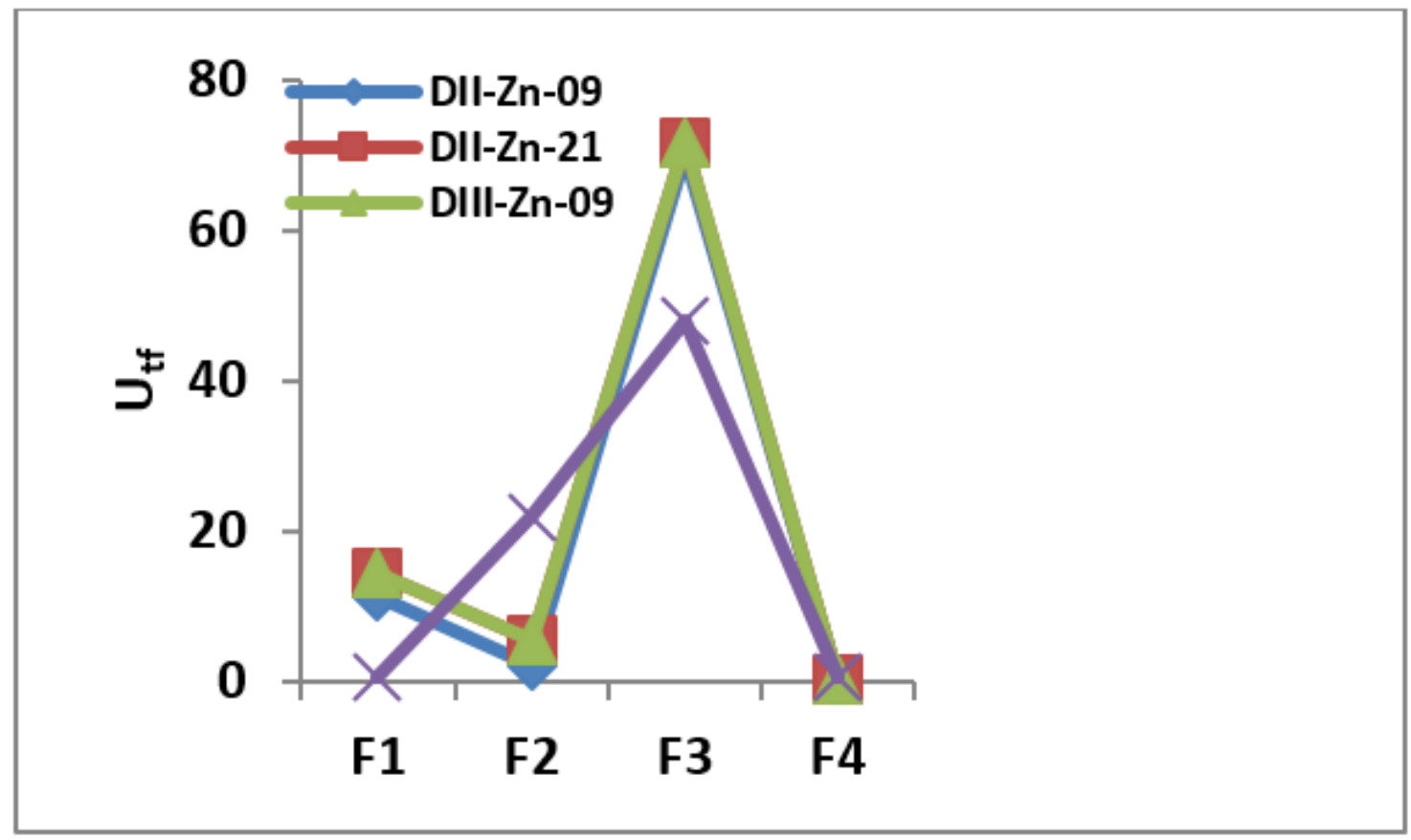

Figure 13 
The long-term evolution of the $\mathrm{Zn}$ transformations-distribution (fractional contents $\mathrm{U}_{\mathrm{tf}}$ ) in the two dumps

\section{Figure 14}

The long-term evolution of "equilibrium Parameter" $\left(\mathrm{U}_{\mathrm{tf}}\right)$ of the $\mathrm{Pb}$ in the whole dumps

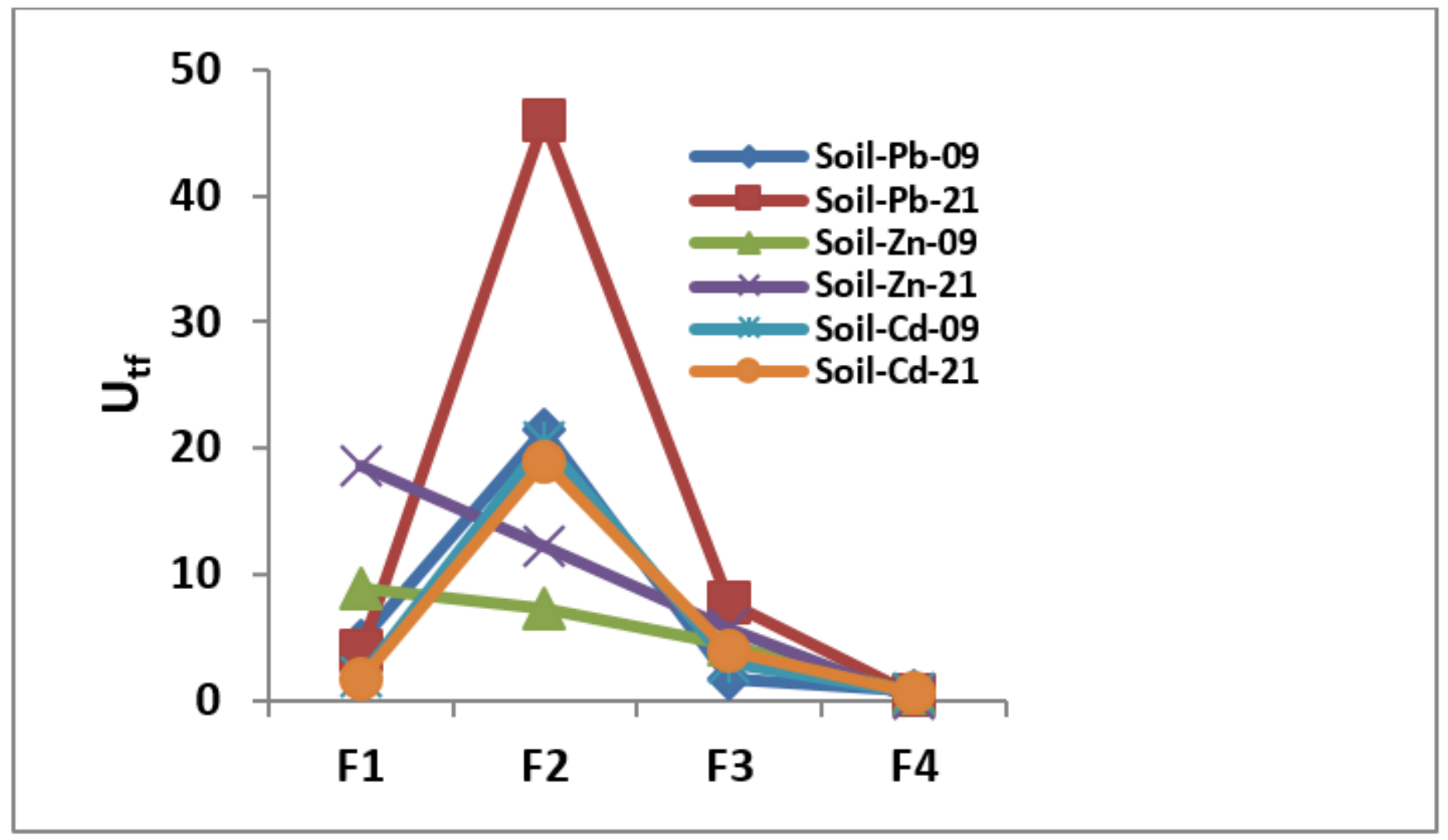

Figure 15

The long-term evolution of the $\mathrm{Pb}, \mathrm{Zn}$ and $\mathrm{Cd}$ transformations-distribution (fractional contents $\mathrm{U}_{\mathrm{tf}}$ ) in soil 